Review Article

\title{
Cardiovascular Mitochondrial Dysfunction Induced by Cocaine: Biomarkers and Possible Beneficial Effects of Modulators of Oxidative Stress
}

\author{
Manuela Graziani, ${ }^{1,2}$ Paolo Sarti, ${ }^{3}$ Marzia Arese, ${ }^{3}$ Maria Chiara Magnifico, ${ }^{3}$ \\ Aldo Badiani, ${ }^{1,4}$ and Luciano Saso ${ }^{1}$ \\ ${ }^{1}$ Department of Physiology and Pharmacology "Vittorio Erspamer", Sapienza University of Rome, Rome, Italy \\ ${ }^{2}$ Drug Addiction and Clinical Pharmacology Unit, University Hospital Umberto I, Sapienza University of Rome, Rome, Italy \\ ${ }^{3}$ Department of Biochemical Sciences "Alessandro Rossi Fanelli", Sapienza University of Rome, Rome, Italy \\ ${ }^{4}$ Sussex Addiction Research and Intervention Centre (SARIC), School of Psychology, University of Sussex, Brighton BN1 9RH, UK
}

Correspondence should be addressed to Manuela Graziani; manuela.graziani@uniroma1.it

Received 1 December 2016; Revised 8 March 2017; Accepted 26 March 2017; Published 16 May 2017

Academic Editor: Daniela Giustarini

Copyright ( 2017 Manuela Graziani et al. This is an open access article distributed under the Creative Commons Attribution License, which permits unrestricted use, distribution, and reproduction in any medium, provided the original work is properly cited.

\begin{abstract}
Cocaine abuse has long been known to cause morbidity and mortality due to its cardiovascular toxic effects. The pathogenesis of the cardiovascular toxicity of cocaine use has been largely reviewed, and the most recent data indicate a fundamental role of oxidative stress in cocaine-induced cardiovascular toxicity, indicating that mitochondrial dysfunction is involved in the mechanisms of oxidative stress. The comprehension of the mechanisms involving mitochondrial dysfunction could help in selecting the most appropriate mitochondria injury biological marker, such as superoxide dismutase-2 activity and glutathionylated hemoglobin. The potential use of modulators of oxidative stress (mitoubiquinone, the short-chain quinone idebenone, and allopurinol) in the treatment of cocaine cardiotoxic effects is also suggested to promote further investigations on these potential mitochondriatargeted antioxidant strategies.
\end{abstract}

\section{Introduction}

Cocaine (COC) use has long been known to cause morbidity and mortality due to its cardiovascular toxic effects $[1,2]$. COC can induce coronary and systemic vasoconstriction and arrhythmias, such as atrial and ventricular fibrillation [3], contraction band necrosis, atherosclerosis, and chest pain [4] as well as acute myocardial infarction [5], up to weeks after last consumption [6], even in presence of normal coronary arteries [7].

The pathogenesis of cardiovascular toxicity related to COC use has been reviewed recently [8-10]. Direct (block of voltage-dependent $\mathrm{K}^{+}$and $\mathrm{Na}^{++}$channels) and indirect (actions of catecholamines and their oxidation products on $\alpha$ - and $\beta$-adrenergic receptors) are suspected to be the primary pathogenic mechanisms.
The fundamental role of oxidative stress (OS) in COCinduced cardiovascular toxicity is well established $[8,11]$. Moreover, formation and accumulation of reactive oxygen species (ROS) as a consequence of $\alpha$ - and $\beta$-adrenergic receptors stimulation $[12,13]$, as well as of enzymatic or nonenzymatic catabolism of catecholamines [14, 15], have been demonstrated in cardiac and vascular cells. Mitochondrial dysfunction leading to the production of ROS is implicated in cardiovascular toxicity $[16,17]$. Furthermore, a number of drugs (e.g., anticancer drugs, antiviral drugs, oral antidiabetic drugs, and recreational drugs) have been demonstrated to induce toxic effects as a consequence of mitochondrial dysfunctions [18]. An important contribution of mitochondria in COC-induced OS and ROS production has been shown in experimental in vivo models $[19,20]$ and in the culture of rat cardiomyocytes [21]. In cardiomyocytes, the 
mitochondria themselves could become the target of COCinduced OS, due to ROS accumulation.

A better understanding of the role of mitochondrial dysfunction in COC-induced cardiovascular toxicity will help to select the most appropriate biological markers and to develop novel mitochondria-targeted antioxidant strategies. The purpose of the present paper is to review the state-ofthe-art study of mitochondrial involvement in ROS production associated to COC-induced cardiovascular toxicity. In particular, we focused on the identification of possible biological markers of OS and the possible beneficial effects of OS modulators.

\section{Mitochondrial Toxicity and Molecular Targets}

The molecular mechanisms by which drugs of abuse, COC particularly, attack tissues' integrity is an issue of paramount importance. Pioneering experiments carried out using epithelial cell cultures [22] or animal models, such as mice [23, 24], have clearly suggested an involvement of mitochondrial chemistry based on the impairment of the respiratory chain with the rise of cytotoxic (ROS) species.

\subsection{Mitochondrial Energy Production and Electron Transport} Chain. In cells, most of the ATP is synthesized by the mitochondria via a proton electrochemical potential gradient, $\Delta \mu \mathrm{H}^{+}$[25]. Under physiological conditions, the mitochondria are maintained operative by a resident mitochondrial DNA in synergy with nuclear DNA, both regulating fusion and fission and mitophagy dynamics of the organelles [26] and, indeed, the expression and activity of the respiratory chain electron transfer (eT) complexes. These complexes, at the level of the inner mitochondrial membrane, either collide among themselves randomly [27], the hypothesis later on reconsidered by [28], or are organised in supramolecular structures of the individual complexes [29]. Relevant to cell bioenergetics, the structural stability of the supercomplexes and the functional performance of the respiratory chain both have been shown to be modulated by the mitochondrial membrane potential [30] and the protein complexes phosphorylation. In addition and possibly related to the cocaine-dependent chemistry involving the proteomembrane complexes, the functional performance of the supercomplexes has been shown to strongly depend on the membrane lipid composition and lipid peroxidation [31]. Regardless of whether organised as individual entities or as supercomplexes, the respiratory chain components enable the redox chemistry and the $\mathrm{H}^{+}$translocation across the inner mitochondrial membrane to occur, ensuring the built up and maintenance of the proton-electrochemical gradient used by the mitochondrial ATPase to synthesize the ATP $[25,32]$.

Relevant to the COC-induced chemistry, the mitochondrial function appears affected both directly, particularly at the level of complex I [33], and indirectly, due to production of reactive oxygen and nitrogen species (ROS and RNS), both strongly affecting mitochondrial complex IV and permeability and fluidity of the membranes. The mitochondrial ATP synthesis depends on the cell metabolism, and the functional status of the molecular machinery is modulated at several levels, principally by the energetic demand and by the substrates availability; in this context, $\mathrm{Ca}^{2+}$ plays a crucial role.

2.2. Mitochondria and $\mathrm{Ca}^{2+}$ Homeostasis. In the frame of the molecular changes induced by COC, it is worth to recall its interference with the cell integrated $\mathrm{Ca}^{2+}$ signaling and homeostasis, whose network although intensively studied is still only partly understood [34]. A complex set of equilibria and chemical reactions tightly controls the flux of $\mathrm{Ca}^{2+}$ within all cell organelles and among specific molecular components of the extracellular and the intracellular cell compartments [34-37].

In the extracellular space, $\mathrm{Ca}^{2+}$ concentration is in the $\mathrm{mM}$ range, whereas in the cytoplasm of a resting cell is $\sim 10^{2} \mathrm{nM}$ [38]. The large concentration gradient is maintained by a dynamic equilibrium, involving a finely integrated $\mathrm{Ca}^{2+}$ controlling molecular machinery $[34,39]$ including a variety of plasma membrane $\mathrm{Ca}^{2+}$ channels, receptors, exchangers, pumps, binding proteins, chaperons, and transporters (Figure 1).

In the cell, the intracellular $\mathrm{Ca}^{2+}$ ions are accumulated into specific cell compartments, the so-called $\mathrm{Ca}^{2+}$ stores. These are the endoplasmic/sarcoplasmic reticulum (ER, for simplicity), the mitochondria, and to some extent the Golgi apparatus, together with the cell nucleus and other organelles, such as the lysosomes and peroxisomes. The $\mathrm{Ca}^{2+}$ concentration in the stores may rise up to 1 or 2 orders of magnitude $(1-10 \mu \mathrm{M})$ higher than that in the cytoplasm, the value depending on the actual cell compartment, and its functional state [40-42].

The mitochondria and ER are responsible for the accumulation in the stores of most $\mathrm{Ca}^{2+}$ contributing, respectively, to microcompartmentalization of up to $25 \%$ and $75 \%$ $\mathrm{Ca}^{2+}$. These compartments are tightly interconnected at specialised sites named mitochondrial-associated membranes (MAM). At this level, the side-by-side proximity between ER and the mitochondria allows the transfer of $\mathrm{Ca}^{2+}$ ions to the mitochondria from proteins and chaperons of the ER. This process occurs via specific channels such as the inositol-tri-phosphate receptors and the ryanodine receptors. At the level of the outer mitochondrial membrane (OMM), $\mathrm{Ca}^{2+}$ ions are transported from the cytoplasm into the intermembrane space (IMS) through the voltage-dependent anion channel (VDAC): this reaction uses ATP; thus, once promoted, ATP synthesis is stimulated. The transport, across the inner membrane of $\mathrm{Ca}^{++}$from the IMS to the mitochondrial matrix, is mainly contributed by the mitochondrial calcium uniporter (MCU), an ion channel that selectively drives the $\mathrm{Ca}^{2+}$ entry into the matrix. Transport occurs in synergy with two complexes named the mitochondrial $\mathrm{Ca}^{2+}$ uptake 1 (MICU1) and the mitochondrial $\mathrm{Ca}^{2+}$ uptake 2 (MICU2), together setting the threshold for the $\mathrm{Ca}^{2+}$ uniporter activity, also mediated by the essential MCU regulator (EMRE) [43]. It is worthy to point out that the mitochondrial $\mathrm{Ca}^{2+}$ loading and its back release to ER take part in the physiological, vital ion-buffering system, while the mitochondrial $\mathrm{Ca}^{2+}$ overloading most often paves the way to apoptosis or even to cell irreversible damage. 


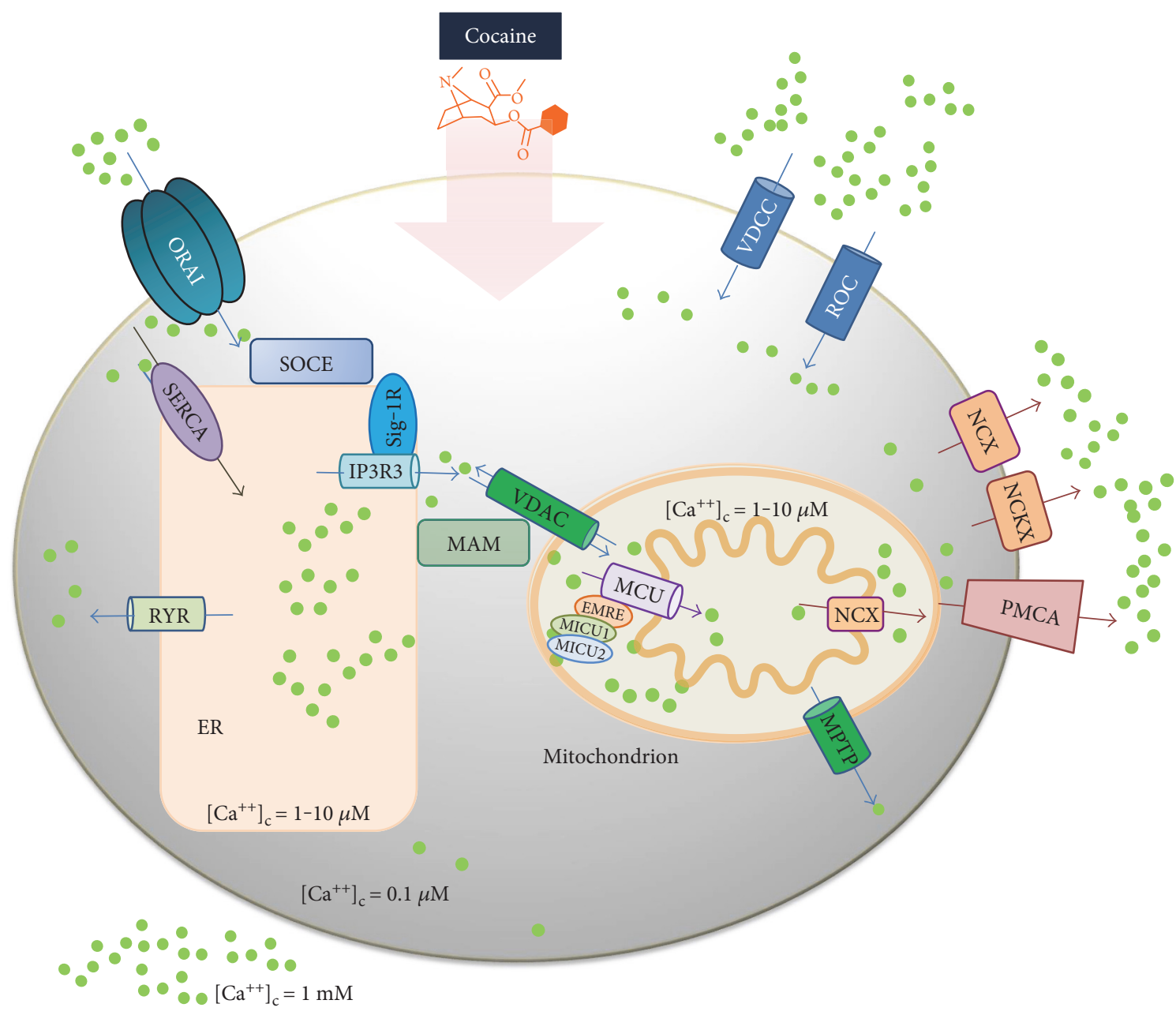

FIGURE 1: Main players of the cell $\mathrm{Ca}^{2+}$ molecular machinery as putative cocaine targets. Ideal intracellular $\mathrm{Ca}^{2+}$ concentration is maintained through complex equilibria among the extracellular space $(1 \mathrm{mM})$, the cytoplasm $(0.1 \mu \mathrm{M})$, and the cellular stores $(1.0-10 \mu \mathrm{M})$, such as the mitochondrion, the endoplasmic reticulum (ER), the Golgi apparatus, and nucleus. The ion trafficking occurs via a variety of selective membrane channels, $\mathrm{Ca}^{2+}$-binding proteins and transporters and ion exchangers and receptors, altogether responsible for $\mathrm{Ca}^{2+}$ import, export, and homeostasis. Import occurs at the level of (i) cell plasma membrane through the calcium release-activated $\mathrm{Ca}^{2+}$ channel protein 1 (ORAI1), the store-operated calcium entry channels (SOCE), and specific receptor-operated channels (ROC) such as AMPA, NMDA, TRPC, and the voltage-dependent calcium channels (VDCC); (ii) endoplasmic reticulum (ER) through the sarco/endoplasmic reticulum calcium ATPase (SERCA); (iii) mitochondria intermembrane space through the voltage-dependent anion channel (VDAC); and (v) in the matrix by the mitochondrial uniporter (MCU), in synergy with the mitochondrial calcium uptake (MICU) system. Extrusion occurs at the level of (i) cell plasma membrane mainly by the plasma membrane calcium ATPase (PMCA) and the sodium calcium exchangers (NCX) also potassium-dependent (NCKX) and (ii) the ER by the ryanodine (RYR) and the inositol 1,4,5-trisphosphate receptors (I P3R), as well as by the mitochondrial permeability transition pore (MPTP).

Uncontrolled mitochondrial $\mathrm{Ca}^{2+}$ accumulation rapidly induces, in fact, a decrease of the mitochondrial membrane potential $(\Delta \Psi)$ leading to pathological production of ROS, RNS with opening of the mitochondrial permeability transition pore (MPTP), and release of cytochrome $c$ and other proapoptotic components. The $\mathrm{Ca}^{2+}$ extrusion into the extracellular compartment, therefore, is also under tight control: it occurs via (i) the plasma membrane-associated $\mathrm{Ca}^{2+}$ ATPase pump (PMCA), extruding against an unfavourable electrochemical gradient, $1 \mathrm{Ca}^{2+}$ ion per hydrolysed ATP and (ii) the potassium-independent $\mathrm{Na}^{+} / \mathrm{Ca}^{2++}$ exchanger (NCX) and the potassium-dependent exchanger (NCKX) [44].

According to recent reports $[45,46]$, COC interferes with the intracellular $\mathrm{Ca}^{2+}$ distribution and trafficking. The interference has been proposed to occur at the level of the store-operated calcium entry (SOCE) system and particularly at the sigma-1 receptor site (Sig-1R) [47]. This is an intracellular chaperone embedded in the endoplasmic reticulum and is responsible for $\mathrm{Ca}^{2+}$ loading into the intracellular stores, the mitochondria included. The functional activity of Sig$1 \mathrm{R}$ was shown to be depressed by COC with impairment of the $\mathrm{Ca}^{2+}$ equilibrium among the cell cytoplasm and stores $[40,48]$. It is worth noticing that the inhibition of SOCE via COC binding at the Sig-1R [45], if confirmed, might lead to even opposite pathophysiological effects. Depending on the extent of binding and duration of SOCE inhibition, the electrophoretic transfer of the positively charged $\mathrm{Ca}^{2+}$ in the mitochondrial matrix could, initially, lead to a slight 
depression of the mitochondrial $\Delta \Psi$, counterbalanced by stimulation of ATP synthesis. No wonder, therefore, the $\mathrm{COC}$ induced mitochondrial $\mathrm{Ca}^{2+}$ loading might be overlooked. On the opposite, the persistence of the mitochondrial $\mathrm{Ca}^{2+}$ loading leads to the opening of the MPTP and triggers the apoptotic programme, with release of cytochrome $c$ and other proapoptotic components [34, 37, 49-52]. Accordingly, COC-treated rat astroglioma cells had shown a dosedependent manner depression of mitochondrial $\Delta \Psi$ and a disruption of cell morphology [53].

2.3. Mitochondria, ROS, and RNS Production in the Pathogenesis of Cardiovascular Toxicity. Cardiomyocytes undergo incessant contractions, their mitochondria requiring a regular supply of $\mathrm{O}_{2}$ and reducing substrates. Normally, during mitochondrial respiration, the vast majority of $\mathrm{O}_{2}$ is reduced to water via the electron transfer $(\mathrm{eT})$ chain $\left(4 \mathrm{e}^{-} / \mathrm{O}\right.$ atom), and only a small oxygen amount (0.1-2\%) undergoes a 1- or 2-electron reduction, with formation of highly reactive partially reduced species, among which $\mathrm{H}_{2} \mathrm{O}_{2}$ and the superoxide radical ion $\left(\mathrm{O}_{2}^{-\cdot}\right)$ are the best representatives. These, when produced at sub- $\mu$ molar, nanomolar levels contribute to the formation of the cellular pool of physiological ROS that plays crucial signaling roles in a variety of conditions. Similarly, under normal conditions, also a number of more or less stable nitrogen oxides can be detected in the cells and tissues (RNS). These include nitric oxide (NO) and peroxynitrite $\left(\mathrm{ONOO}^{-}\right)$, that is, highly reactive species responsible, particularly the latter, for cell redox reactions that are often highly detrimental, such as protein nitrosation and membrane nitration. Among them, NO is present in the environment at up to nanomolar concentrations, as produced by the cell constitutive NOSs (eNOS and nNOS).

When present in large excess by the inducible iNOS $(\geq \mu \mathrm{M}), \quad \mathrm{NO}$ is a potent inhibitor of the mitochondrial respiration [54]. Noticeably, in the presence of enough $\mathrm{O}_{2}(5 \div 20 \mu \mathrm{M})$ and a suitable electron flux through the respiratory chain sustained by the mitochondrial substrates and reduced cytochrome $c$, the presence of nanomolar NO does not depress (significantly) cell respiration. Interestingly, from the bioenergetics signaling point of view, under these conditions, the apparent affinity for $\mathrm{O}_{2}\left(K_{M, \mathrm{O} 2}\right)$ of cytochrome $c$ oxidase ( $\mathrm{CcOX}$ ) rises [55], and the mitochondria become sensitive to the $\mathrm{O}_{2}$ concentration, thus ready to shift to glycolytic production of ATP $[56,57]$. Under persistent hypoxic conditions, when the mitochondrial respiratory chain experiences for longer times a too low (insufficient) $\mathrm{O}_{2}$ concentration, a different landscape could be depicted. The rapid activation of constitutive NOS is observed together with the rise of NO concentration, whose increase, however, induces a depression to the oxidative phosphorylation due to, particularly, the inhibition of not only complex IV but also to some extent of complex I [57]. As observed in neurons, glycolysis takes place to compensate for the decreased ATP synthesis, a finding not directly shown, however, in cardiomyocytes. In addition, the cell environment turns acidic facilitating the conversion of nitrite $\left(\mathrm{NO}_{2}^{-}\right)$into nitric oxide. $\mathrm{NO}$, in the presence of $\mathrm{O}_{2}^{-}$, at a diffusion-limited rate [58], forms the highly cell detrimental peroxynitrite, $\mathrm{ONOO}^{-}$, initiating and sustaining a vicious circle that leads to permanent blockage of the mitochondrial eT $[59,60]$. At this point, the reaction mechanisms controlling the cell steady-state level of ROS and RNS might become severely insufficient.

In summary, due to complex I inhibition by COC, the cardiomyocytes are likely called to face in rapid sequence, though not necessarily in this chronological order, hypoxia and cell acidification and rise of ROS/RNS species. As a consequence, cell survival might be at risk and cell death committed. Most frequently, the chemical species formed are strong oxidizing agents such as hydrogen peroxide, hypochlorous acid and peroxynitrite ion, and some of them are radical, for example, the nitric oxide and superoxide anion or the hydroxyl radical. Pathophysiologically relevant, not only cardiomyocytes but also the endothelial cells and the leucocytes, activated during the oxidative burst and the inflammation response, are responsible for the environmental physicochemical change and the uncontrolled ROS and RNS production. Altogether, the events point to excess ROS/RNS as being responsible for the production of cell detrimental effects, thus linking together, at the mitochondrial level, the OS, the early inflammation response, and cell death.

2.4. Crosstalk between the NO Chemistry and Cocaine. NO is actively produced by the NOSs [61] or it is chemically generated all throughout our organism. Three NOS isoforms have been identified and named after the cell tissues where they were first detected: the endothelial NOS (eNOS) from the endothelium, the neuronal NOS (nNOS) from the nervous system, and the inducible NOS (iNOS) from immunocompetent cells. These three isoforms share a substantial sequence homology (50-60\%) and some basic features such as one catalytic Fe metal, the cofactors, and the substrates' binding sites. The expression and activity of the iNOS strongly depend on cell stressors but are independent on cell $\mathrm{pCa}^{2+}$ whereas eNOS and nNOS, both constitutive enzymes, are finely regulated by the concentration of cytosolic $\mathrm{Ca}^{2+}$. Relevant to the NO chemistry, COC is known to react also with the NMDA receptor [62], whose activation is induced via $\mathrm{Ca}^{2+}$ rise, activity of nNOS, and NO production [63] (Figure 2); a pathway was also reported for morphine [55].

NOSs use arginine and $\mathrm{O}_{2}$ as substrates. The affinity for $\mathrm{O}_{2}$ is not equally distributed among the NOS isoforms. The eNOS shows the highest affinity $\left(K_{M} \sim 5 \mu \mathrm{M}\right)$, comparable to that of the mitochondrial $\mathrm{CcOX}$, while nNOS and iNOS have a lower $\mathrm{O}_{2}$ affinity $[57,64]$.

Under hypoxic conditions, therefore, the $\mathrm{O}_{2}$ availability can limit the enzymatic production of NO by the NOSs. During hypoxia, maintenance of the NO homoeostasis may require the release of $\mathrm{NO}$ from bulk nitrosothiols, or at the expenses of metal ions $\left(\mathrm{Fe}^{2+}\right.$ and $\left.\mathrm{Cu}^{+}\right)$bound to proteins or free in solution. These ions catalyze the reduction of nitrite to $\mathrm{NO}$ and particularly at acidic $\mathrm{pH}$ and under hypoxic conditions [65].

In agreement with previous reports [66-71], the involvement of the NO chemistry in the development of COC addiction has been recently confirmed by the results of the selective 7-nitroindazole (7-N) inhibition of nNOS, induced on Wistar rats. The animals when preliminarily treated with 


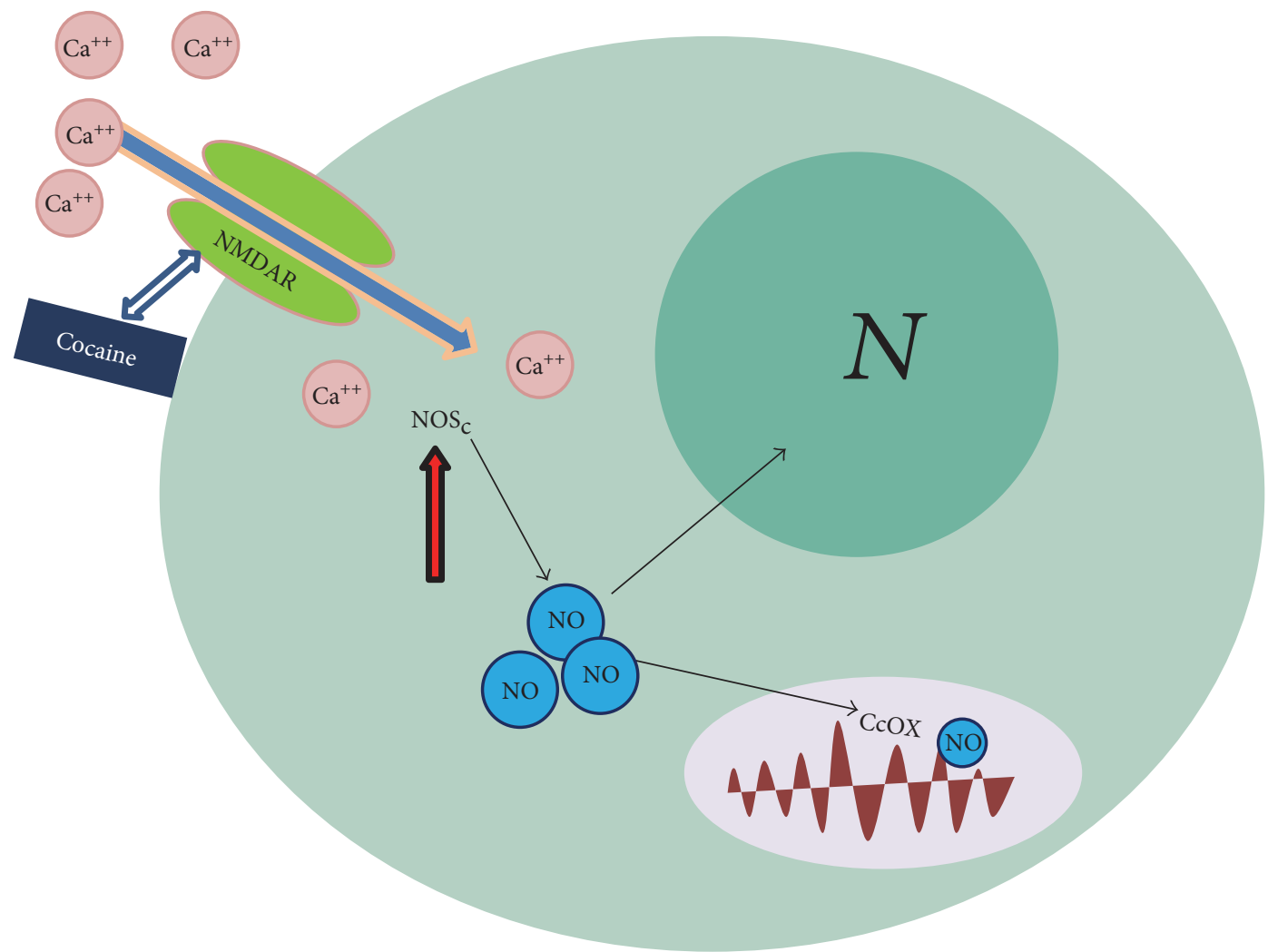

FIGURE 2: NMDA-receptor targeting by cocaine (hypothesis). The scheme is drawn by analogy to the functional effects observed at the level of the cell nitric oxide chemistry and detected when treating glioma cells in culture with morphine [55]. It shows the activation of the cocainemediated NMDA-R, leading to cytoplasmic $\mathrm{Ca}^{++}$rise, activation of the constitutive NOS, and release of NO, targeting mitochondrial respiratory chain complexes.

7-N showed a significant attenuation of the COC withdrawal symptoms, and their brain-isolated synaptosomes displayed both the reversal of the drug mitochondrial depression and the decrease of GSH levels [72]. The fundamental role of mitochondrial GSH in protecting membrane functions was also observed in an experimental model of COC-induced hepatotoxicity in rats [73].

In humans, PET measurements performed using C-11COC have shown in the early 90s that COC redistributes in most organs and tissues although following different kinetics (from seconds to several minutes) [74]. Redistribution likely includes the skin, and heavy COC abusers often display unpleasant skin signs, whose molecular mechanisms, however, are still mostly obscure. In this framework, it may be worthy to recall that the systemic administration of COC to male Sabra rats, thereafter subjected to skin biopsies, was able to rise the iNOS and xanthine oxidase (XO) activity prevented by specific inhibitors, such as the L-nitrosoarginine methyl-ester (L-NAME) and the oxypurinol (OP), respectively; the same authors reported similar results using human keratinocytes in culture [75]. The proposition put forward was that the oxidative-oxynitrosative damage was bound to the skin accumulation of superoxide and nitric oxide radicals, readily forming peroxynitrite [58] and lipoperoxides, along with a marked decrease of ROS/RNS scavengers such as reduced glutathione (GSH) and ascorbic acid (AA) [75]. This hypothesis appears fully consistent with the suggestion that the $\mathrm{COC}$ oxidative metabolites, and among them particularly, the nitrogen $\mathrm{N}$-derivatives, are involved in the adverse biological effects observed in the human body, at least when chronically exposed to COC [76].

\section{Mitochondria and Cocaine-Induced Cardiovascular Toxicity}

As mentioned above, the role of mitochondria in the pathogenesis of COC-induced cardiovascular toxicity is well recognized $[8,20,21,33,77]$. COC may induce mitochondrial dysfunction in cardiomyocytes and in endothelial cells, based on direct and indirect mechanisms (Figure 3). Owing to its pathophysiological relevance at both cardiomyocytes and endothelial level, it may be worth to summarize the evidence supporting the hypothesis that COC is likely responsible for a specific mitochondrial impairment.

3.1. Cardiomyocytes. Notably, stimulation (and overstimulation) of $\beta$-adrenergic receptors ( $\beta$-AR) triggers the release of $\mathrm{Ca}^{2+}$ in the mitochondria [78]. Indeed, stimulation of $\beta$ adrenergic receptors increases $\mathrm{Ca}^{2+}$ levels in the cytosol, through the activation of protein kinase A (PKA): increased cytosolic $\mathrm{Ca}^{2+}$ leads in turn to phosphorylation of $\mathrm{Ca}^{2+}$-protein substrates and to the transfer of $\mathrm{Ca}^{2+}$ into the mitochondria [79]. As mentioned above (Section 2.2), excess mitochondrial $\mathrm{Ca}^{2+}$ impairs ATP production, causing nitro-oxidative stress 


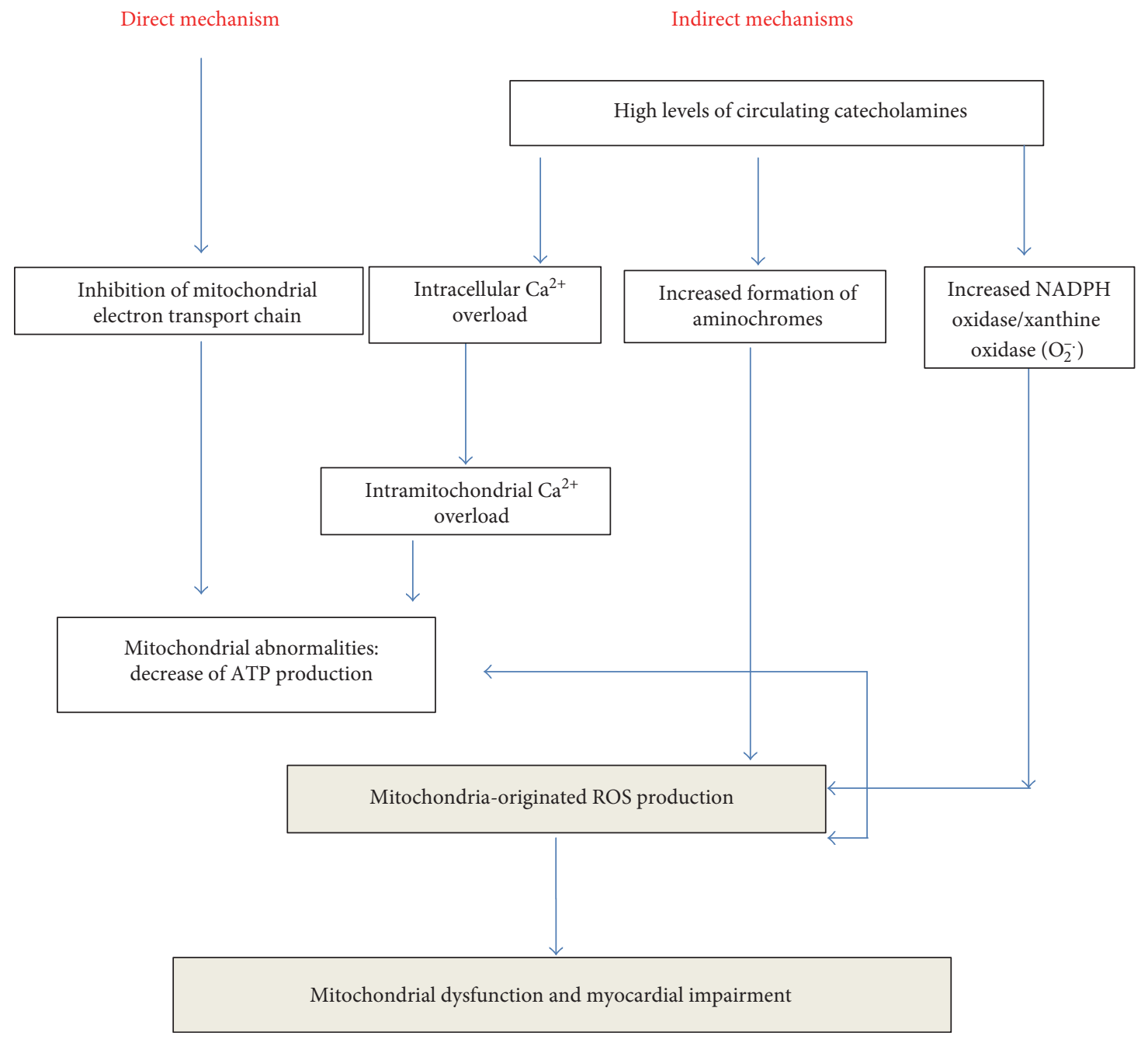

Figure 3: Cocaine-induced mitochondrial dysfunction.

with changes in permeability of the mitochondrial membrane, altogether leading to structural degeneration of cardiomyocytes [9, 80,81]. Overproduction of mitochondrial ROS/RNS is in fact responsible for the massive opening of MPTP $[16,82]$ resulting in a further dysfunctional and structural degeneration of these organelles.

As already mentioned in Section 2.1 in isolated brain and liver mitochondria [83] and in culture rat myocardial cells, COC at high concentration had shown to inhibit complex I (NADH dehydrogenase) activity [33] leading in turn to inhibition of ATP synthesis. Accordingly, Fantel and colleagues [84] demonstrated a COC inhibitory effect on mitochondria respiration in rat embryo tissues. Importantly, in a model of myocardial ischemia-reperfusion, it has been demonstrated that a reduction in complex I activity may enhance ROS production by complex III [85].

A further mitochondrial role in COC myocyte toxicity is suggested by experimental studies, in which a mitochondriadependent apoptosis was observed [77, 86, 87]. Indeed, in chronic COC-treated rats [77] and in cultured fetal [87] and adult [86] myocytes, COC induced apoptosis. The cytotoxic effects on cardiomyocytes were related to the release of cytochrome $c$ from the mitochondria with activation of caspase-9 and caspase-3, whose inhibition blocked cell apoptosis [87]. Accordingly, a COC-induced apoptosis associated with the release of cytochrome $c$ was observed also in cultured bovine coronary artery endothelial cells [88]. Interestingly, from the mechanistic point of view, in experiments carried out using adult rat ventricular cardiac myocytes, the caspase inhibition decreased the $\beta$-AR-stimulated apoptosis [86].

Apoptosis activation was also observed in the cerebral cortex of human COC addicts [89]. The postmortem brain study showed a significant reduction in the content of mitochondrial cytochrome $c$ in prefrontal cortex: the authors suggest that the downregulation of cytochrome $c$ could represent the induction of a counter regulatory adaptation to brain apoptotic effects induced by COC via mitochondria oxidative stress.

As mentioned above (Section 2.3), the accumulation of ROS/RNS is an important event by which COC may induce mitochondrial dysfunction with subsequent cardiotoxicity. Although the extent of mitochondrial dysfunction produced by COC is still unknown, it is generally accepted that the mitochondria are the main source of ROS production $[90,91]$ meantime being targets of the oxidative stress. 
COC-induced ROS production may occur by mechanisms different from electron leak at the sites of the respiratory chain complexes, namely, by

(i) formation of $\mathrm{O}_{2}^{--}$, during catecolamine oxidation (intramitochondria redox cycling),

(ii) synthesis of $\mathrm{H}_{2} \mathrm{O}_{2}$ by monoamine oxidase (MAO), during oxidative deamination of catecholamines (outer membrane of mitochondria),

(iii) ROS-induced ROS mitochondria formation [92].

Thus, ROS formation has been associated with COCinduced catecholamine release $[8,93]$.

As noted, a crucial role in COC-induced toxicity is played by transformation of catecholamines into aminochromes, that is, the oxidative catecholamine metabolites [93]. Indeed, when the level of catecholamines rises and the enzymes responsible for their catabolism become less efficient, as it might likely occur during COC abuse, catecholamines can undergo oxidation $[14,94]$ with formation of aminochromes (adrenochrome, dopachrome, and noradrenochrome); these molecules are very active from the redox cycling point of view. In bovine heart, it has been demonstrated that adrenochrome is reduced into semiquinone by mitochondrial complex I [95] inducing in cardiomyocyte mitochondria the formation of $\mathrm{O}_{2}^{-\cdot}[9,94,96]$.

Genova and coworkers [97] had shown that mitocondrial complex I is involved both in initial generation of superoxide and in the reduction of adrenochrome to its semiquinone form. Furthermore, the superoxide anion $\mathrm{O}_{2}^{-}$in turn increases the adrenaline oxidation rate [14, 97]. Thus, the mitochondria, on one side, are largely responsible for cardiomyocyte oxidative stress, while on the other side, they are themselves targets of the stress. In addition, it is worth mentioning that the adrenochrome inhibits the oxidative phosphorylation of cardiac mitochondria [98] and leads to further enhancement of mitochondrial impairment.

Also MAO, flavin enzymes located in the outer membrane of mitochondria, are responsible for oxidative deamination of catecholamines, resulting in synthesis of $\mathrm{H}_{2} \mathrm{O}_{2}$ leading in turn to highly reactive $\mathrm{HO} \cdot[93,99]$. Accordingly, in an experimental model in rats, it has been demonstrated that myocardial oxidative stress could be partially prevented by MAO inhibitors [100].

A further contribution to the stimulation of $\mathrm{COC}$-induced mitochondrial ROS production may be derived from NADPH oxidase (Nox) and XO activity, also contributing to ROS generation in cardiac tissue $[8,13]$. Indeed, the $\alpha 1$-adrenoceptor stimulation increases the activation of Nox $[13,101]$ which in turn produces $\mathrm{O}_{2}^{-}$.

In an in vivo model of COC-induced diastolic dysfunction, it has been shown that 7 days of COC administration induces an increase of mitochondrial ROS production in cardiac fibers, with uncoupling of mitochondrial respiration [20]. It is worth noticing that over a similar period of incubation COC administration induces also the activation of Nox and XO, whose functional onset might precede mitochondrial failure [102]; this finding suggests that it is the
ROS production by the Nox and XO that first triggers the ROS production by mitochondria not vice-versa [19].

Accordingly with this hypothesis, it has been suggested that MitoQ [20] and allopurinol [19] treatments may prevent oxidative stress and attenuate COC-induced cardiotoxicity.

3.2. Endothelial Cells. In endothelial cells, the mitochondrial content is reduced, compared to other cell lines [103, 104]. Thus, by comparison with cardiac myocytes and other cell types characterized by higher energy requirements, one might expect, from the quantitative point of view (only), a relatively smaller production by mitochondria of COCinduced reactive species. This notwithstanding ROS production by endothelial cell and their contribution to development of heart disease [104] has been demonstrated in rat [105] and in mouse [106] models. In cultured endothelial cells used as experimental models of ischemia/reperfusion, extensive amounts of ROS were observed [107].

The pro-oxidant activity of $\mathrm{XO}$ has been observed [108], and XO from endothelial vasculature has been proposed as the main ROS enzymatic source [93]; accordingly, patients with ischemic cardiomyopathy oxypurinolinduced inhibition of XO had shown improved myocardial contractility [109]. In endothelial cells, the activity of XO increases in $\mathrm{I} / \mathrm{R}$ and it is a source of $\mathrm{O}_{2}$ when in the presence of high levels of hypoxanthine.

\section{Possible Biomarkers of Cocaine-Induced Oxidative Stress}

Notably, biological markers (biomarkers) may be useful to quantify biological processes, disease state, or therapy prediction and therapeutic tools $[110,111]$. The increase in understanding mechanisms of oxidative stress in drug $[8,112,113]$ and alcohol $[114,115]$ addiction has led to identify oxidative stress markers, that, although not validated and specific, could help to evaluate oxidative status in drug abusers, both in acute and chronic use and in withdrawal syndrome $[116,117]$. In Table 1, the proposed peripheral biomarkers of OS and relative references are listed.

In a recent study [117], it has been suggested that thiobarbituric acid reactive substances (TBARS) and brainderived neurotrophic factor (BDNF) could be biomarkers for evaluation of severity of crack COC use. Furthermore, the authors found in male crack COC users a positive correlation between TBARS levels and severity of abuse during withdrawal syndrome. Notably, TBARS are an aspecific biomarker of peripheral oxidative stress, consisting of a quantification method for malondialdehyde (MDA) and stabile product of lipid peroxidation [118, 119]. Accordingly with clinical data, experimental studies in rats showed an increase in MDA levels in the heart, both after COC selfadministration and extinction training [120] and after COC injection $[121,122]$.

Conversely, in a clinical study aimed at evaluating total antioxidant capacity in $\mathrm{COC}$ and methamphetamine subjects [123], no difference was found in MDA blood levels with respect to control. One possible explanation is that discrepancy in results may be due to differences in some 
TABLE 1: Peripheral biomarkers of cocaine-induced oxidative stress.

\begin{tabular}{lccr}
\hline Markers & Sample & Note & References \\
\hline MDA & Plasma & Aspecific biomarker of lipid peroxidation & {$[117,120-123]$} \\
TBARS & Plasma & Aspecific biomarker of lipid peroxidation & {$[117,128]$} \\
BDNF & Plasma & Negative correlation with severity of cocaine use & {$[117,128]$} \\
Glutathionylated Hb & Plasma (RBC) & Increased levels in oxidative stress conditions (i.e., cigarette smokers) & {$[113,140]$} \\
SOD & Plasma (RBC) & Decreased levels of activity & {$[120-122,131]$} \\
\hline
\end{tabular}

BDNF: malodialdehyde; TBARS: thiobarbituric acid reactive substances; BDNF: brain-derived neurotrophic factor; Hb: hemoglobin; RBC: red blood cells; SOD: superoxide dismutase.

characteristics of participants. Indeed, Sordi and coworkers [117] included subjects $(N=49)$ positive for current COC use, while in the study from Walker and coworkers [123], patients $(N=126)$ had used COC within 60 days prior to the test and almost $23 \%$ were positive for use. It can be suggested that the oxidative damage of lipids produced by current COC use, counteracting by antioxidant defense (see below), may shift towards antioxidant systems when the subjects became progressively abstinent.

Even though TBARS are neither specific nor quantitative [119], given that MDA plasma levels showed an increase in acute myocardial infarction $[124,125]$ and also in brain illnesses such as Parkinson's [126] and Alzheimer's [127] diseases, this biomarker may be useful to assess relative level of lipid peroxidation in COC abusers.

An increase in BDNF levels among crack users with respect to control subjects was also found $[117,128]$. The function of this peripheral brain injury biomarker in druginduced neuroadaptation is well known [129], and recent clinical data in chronic schizophrenia patients [130] showed that both BDNF and OS may be involved in the pathophysiology of this disease, suggesting an interaction mechanism between oxidative damage and neurotrophin dysfunction. Further investigations implicating these two peripherally measured biomarkers should contribute to understand the relative implication and interaction of oxidative stress and neurotrophic factors in disorders.

\section{Antioxidant Defense System Biomarkers of Cocaine Oxidative Stress}

Blood peripheral biomarkers of antioxidant enzymes were evaluated in a population of COC user [123], $(N=126$; $18 \%$ abstinent for 1 month and more prior to the inclusion). The results showed no differences in the activities of glutathione peroxidase and catalase between COC user and control subjects, whereas a significant reduction in the SOD activity was observed in erythrocytes.

Accordingly, in a rat model of COC-induced heart injury, Moritz and coworkers [122] had shown that COC long-term administration caused a significant decrease in SOD activity; a biphasic trend in SOD concentration in rat spleen was observed after chronic COC administration in vivo [131] since that, after an early peak, SOD was significantly depleted 24 hours after COC treatment.

Notably SOD are an ubiquitous family of enzymes $[132,133]$ in which actually three distinct isoforms has been identified in humans. SOD1 $(\mathrm{Cu} / \mathrm{ZnSOD})$ is the major intracellular form of SOD, accounting for almost $80 \%$ of total SOD protein and is localized to the outer mitochondrial membrane, while SOD2 (MnSOD) is localized exclusively in the mitochondrial matrix $[134,135]$ and is expressed in the heart, lung, liver, and blood cells. SOD3 is the major SOD of human extracellular matrix of different tissues, mainly expressed in the lung and scarcely in the brain [136].

In the rat liver, $\mathrm{SOD} 1 / \mathrm{Cu}, \mathrm{Zn}$ was found in the mitochondrial intermembrane space and SOD2 was found in the matrix and also in the inner membrane [137]. Recent experimental data in rats [120] indicate no changes in SOD activity (irrespective of the isozyme subclass) in peripheral organs such as the heart and the liver, both during COC selfadministration and during extinction phase (10 days). Conversely, a significant enhancement in SOD activity was found in the hippocampus and in the kidney. The authors suggest that different changes in the activity of SOD in rat brain structures and peripheral tissues may reflect differences in OS status and that increases in the SOD enzymatic activity could correspond to a reduction in MDA concentrations.

Due to its exclusive nuclear-encoded localization in the mitochondrial matrix, SOD2 is considered the main mitochondria antioxidant defense against toxic effects of ROS. So it can be suggested that evaluation of activity of SOD with respect to its isozyme subclasses could be a more specific biomarkers of mitochondrial oxidative stress. A further attention to different isozyme overexpression in specific cell types and tissues may achieve a contribution to better identify specific targets of oxidative stress.

Another peripheral biological marker that might reflect oxidative status in tissues is the level of glutathionylated hemoglobin $(\mathrm{Hb})$. The role of the mechanism of S-glutathionylation (i.e., the conjugation of glutathione to protein cysteine residues catalyzed by glutathione S-transferase $\mathrm{P}$ ) in response to oxidative stress in drug addiction was discussed in a recent review [113]. Protein S-glutathionylation can be considered a protective mechanism associated with elevated oxidative stress in alcohol, heroin, and also in COC abuse. In preclinical studies, acute and chronic COC treatment, but not withdrawal, had shown to increase brain formation of glutathionylated protein and a decrease in expression of GSH-S-transferase P $[138,139]$. Notably most of the glutathionylated proteins are intracellular [110]; to date, in human, the extent of glutathionylation in some pathologies (i.e., diabetes mellitus, hyperlipidemia, and uremia) can be measured only in blood [140], since in red blood cells $\mathrm{Hb}$ accounts for $97 \%$ of protein composition [141]. Importantly, increased levels of glutathionylated $\mathrm{Hb}$ were observed in 
TABle 2: Potential therapeutic use of selective antioxidant compounds for cocaine-induced mitochondrial impairment.

\begin{tabular}{lcc}
\hline $\begin{array}{l}\text { Antioxidant } \\
\text { compounds }\end{array}$ & Mechanism of action & References \\
\hline MitoQ & $\begin{array}{c}\text { Inhibition of XO activity } \\
\text { and protection of mitochondria } \\
\text { membrane potential } \\
\text { Transferring of electron in } \\
\text { mitochondrial respiratory } \\
\text { chain from cytoplasm to } \\
\text { Idebenone } \\
\text { quinone) }\end{array}$ & $\begin{array}{l}\text { complex III (bypass deficiency } \\
\text { in complex I) }\end{array}$ \\
& $\begin{array}{r}\text { Inhibition of XO activity } \\
\text { and consequent rescue of in } \\
\text { Allopurinol }\end{array}$ & {$[152]$} \\
& ATP production & \\
\hline
\end{tabular}

cigarette smokers [142, 143] suggesting that its quantification can be used as a low-invasive clinical biomarker of oxidative stress-associated diseases. To our best of knowledge, no clinical data are present in literature regarding glutathionylated $\mathrm{Hb}$ in $\mathrm{COC}$ addicts.

In conclusion, we further retain that in studies concerning the evaluation of oxidative stress in drug abuse and clinical relevance of relative biomarkers it is important to take into account factors that could significantly influence both oxidative state and antioxidant defense. Physiological (e.g., age, gender, body weight, diet, and lifestyle) and pathologic factors (psychiatric comorbidity, cardiovascular and metabolic illnesses and their relative severity, etc.) as well as drug abuse history [age of onset, duration, polydrug abuse, tobacco smoking, alcohol use, and prevalence of current use (i.e., during last month)] could affect total oxidative state. Only early patient stratification based on their profile could help to identify the most appropriate panels of both diagnostic and prognostic biomarkers and conduct to optimal management for the patients.

\section{Modulators of Oxidative Stress in Mitochondrial Protection: Future Direction}

The use of antioxidants as therapeutic tools is still controversial $[8,144,145]$. In a recent review on potential use of modulators of OS in treatment of COC cardiotoxic effects, Graziani and coworkers [8] underlies that both preclinical and clinical data in literature has not yet been adduced to argue conclusive evidence.

However, the fundamental role of mitochondria in COCinduced OS strongly suggests that mitochondria-targeted intervention could become a pharmacological strategy to prevent and to treat this kind of damage. In Table 2, selective antioxidant compounds for potential therapeutic use in COC toxicity are reported.

In an experimental model of COC-induced cardiac dysfunction, MitoQ (mitoubiquinone) had shown to limit COC-induced left ventricular dysfunction [20]. Accordingly, in vitro studies [146, 147] of rat-stretched cardiomyocytes showed that MitoQ could prevent both mitochondrial damage and increase in $\mathrm{XO}$ activity and protect mitochondrial membrane potential. MitoQ is actually the most studied mitochondria-targeted antioxidant therapeutic compound [148] and some human studies have confirmed its efficacy in some cardiovascular pathologies, such as hypertension, and drug toxicity (alcohol, adriamycin) [47]. To our best of knowledge, no human studies are present in literature on the potential effects of MitoQ in treatment of COC-induced mitochondria toxicity.

On the basis of the abovementioned mechanisms of mitochondria dysfunction induced by COC, other therapeutic tools may be hypothesized.

The short-chain quinone idebenone has been also suggested to be beneficial in mitochondrial dysfunction [149] due to its antioxidant effects [150]. Idebenone proved to rescue ATP levels under conditions of impaired complex I transferring electron in mitochondrial respiratory chain from complex III [151]. The COC toxic effect of inhibition of the activity of mitochondrial complex I [33] may be reversed by some short-chain quinones. Consistent with this capacity of ATP activity rescue, idebenone should be investigated as a possible treatment for COC-induced dysfunction in mitochondrial respiratory chain [152].

In an experimental model of COC-induced diastolic dysfunction, XO activity inhibition by allopurinol [19] had preserved both left ventricular systolic and the decrease in ATP production, confirming the contribution of COCinduced mitochondrial ROS production in cardiac tissue. The protective role of allopurinol was confirmed in human and rat left ventricular (LV) myocytes with volume overload where the increase in ATP demand and the concurrent XOmediated ROS can decrease mitochondrial respiration and contractile function [153] and in remodeling processes after experimental myocardial infarction [154]. To date, some clinical data appear to suggest that pharmacological XO inhibition could represent potential tools for the treatment of human cardiomyopathy [155]. The safety profile of (the old) allopurinol underlies the possibility of testing this $\mathrm{XO}$ inhibitor for further therapeutic interventions.

\section{Conclusion}

In the present paper, the role of cardiovascular mitochondria in COC-induced OS and ROS production was reported. Preclinical and clinical data underlie the fundamental participation of mitochondrial dysfunction to pathogenesis of COC-induced cardiovascular toxicity. As a consequence, possible biological peripheral markers of OS mitochondrial injury may be proposed. Both the antioxidant defense system biomarkers SOD2/MnSOD and glutathionylated $\mathrm{Hb}$ appear to be appropriate peripheral biomarkers of oxidative stress: since clinical data in COC and psychotropic drug users are inadequate to draw any conclusion, it could suggest that additional studies in this population subjects may be performed. Even in the case of potential therapeutic effects of mitochondrial protection, further studies on the proposed antioxidant drugs (MitoQ, idebenone, and allopurinol) will be crucial to assess their effectiveness or inability to counteract mitochondrial dysfunctions induced by cocaine. 


\section{Abbreviations}

\begin{tabular}{|c|c|}
\hline AA: & Ascorbic acid \\
\hline$\beta$-AR: & $\beta$-Adrenergic receptors \\
\hline BDNF: & Brain-derived neurotrophic factor \\
\hline CcOX: & Cytochrome c oxidase \\
\hline COC: & Cocaine \\
\hline$\Delta \Psi:$ & Mitochondrial membrane potential \\
\hline eNOS: & Endothelial NOS \\
\hline ER: & Endoplasmic/sarcoplasmic reticulum \\
\hline eT: & Electron transfer \\
\hline GSH: & Glutathione \\
\hline $\mathrm{Hb}:$ & Hemoglobin \\
\hline $\mathrm{H}_{2} \mathrm{O}_{2}$ : & Hydrogen peroxide \\
\hline $\mathrm{HO} \cdot:$ & Hydroxyl radical \\
\hline HO: & Heme oxygenase \\
\hline iNOS: & Inducible NOS \\
\hline IMS: & Intermembrane space \\
\hline L-NAME: & L-Nitroso-arginine methyl-ester \\
\hline MAM: & Mitochondrial-associated membranes \\
\hline MAO: & Monoamine oxidase \\
\hline MDA: & Malondialdehyde \\
\hline MCU: & Mitochondrial calcium uniporter \\
\hline MICU1: & Mitochondrial $\mathrm{Ca}^{2+}$ uptake 1 \\
\hline MICU2: & Mitochondrial $\mathrm{Ca}^{2+}$ uptake 2 \\
\hline MitoQ: & Mitoubiquinone \\
\hline MPTP: & Mitochondrial permeability transition pore \\
\hline NAC: & N-Acetylcysteine \\
\hline nNOS: & Neuronal NOS \\
\hline $\mathrm{NO} \cdot:$ & Nitric oxide \\
\hline Nox: & NADPH oxidase \\
\hline NMDA: & N-Methyl-D-aspartate \\
\hline NOS: & NO synthase \\
\hline $\mathrm{O}_{2}^{-}:$ & Superoxide anion \\
\hline OMM: & Outer mitochondrial membrane \\
\hline ONOO-: & Peroxynitrite ion \\
\hline OP: & Oxypurinol \\
\hline OS: & Oxidative stress \\
\hline OXPHOS: & Oxidative phosphorylation \\
\hline PKA: & Protein kinase A \\
\hline PMCA: & $\begin{array}{l}\text { Plasma membrane associated } \mathrm{Ca}^{2+} \text { ATPase } \\
\text { pump }\end{array}$ \\
\hline RNS: & Reactive nitrogen species \\
\hline ROS: & Reactive oxygen species \\
\hline Sig-1R: & Sigma-1 receptor site \\
\hline SOCE: & Store-operated calcium entry \\
\hline SOD: & Superoxide dismutase \\
\hline TBARS: & Thiobarbituric acid reactive substances \\
\hline XO: & Xanthine oxidase \\
\hline EMRE: & Essential MCU regulator \\
\hline VDAC: & Voltage-dependent anion channel \\
\hline NCX: & Potassium-independent $\mathrm{Na}^{+} / \mathrm{Ca}^{2++}$ exchanger \\
\hline NCKX: & Potassium-dependent $\mathrm{Na}^{+} / \mathrm{Ca}^{2++}$ exchanger \\
\hline $7-\mathrm{N}:$ & 7-Nitroindazole. \\
\hline
\end{tabular}

\section{Conflicts of Interest}

The authors declare that there is no conflict of interests regarding the publication of this paper.

\section{References}

[1] D. L. Coleman, T. F. Ross, and J. L. Naughton, "Myocardial ischemia and infarction related to recreational cocaine use," The Western Journal of Medicine, vol. 136, no. 5, pp. 444446, 1982.

[2] R. Virmani, M. Robinowitz, J. E. Smialek, and D. F. Smyth, "Cardiovascular effects of cocaine: an autopsy study of 40 patients," American Heart Journal, vol. 115, no. 5, pp. 1068-1076, 1988.

[3] R. A. Lange, R. G. Cigarroa, C. W. Yancy Jr et al., "Cocaineinduced coronary-artery vasoconstriction," The New England Journal of Medicine, vol. 321, no. 23, pp. 1557-1562, 1989.

[4] S. Maraj, V. M. Figueredo, and D. Lynn Morris, "Cocaine and the heart," Clinical Cardiology, vol. 33, no. 5, pp. 264-269, 2010.

[5] J. E. Weber, C. R. Chudnofsky, M. Boczar, E. W. Boyer, M. D. Wilkerson, and J. E. Hollander, "Cocaine-associated chest pain: how common is myocardial infarction?" Academic Emergency Medicine, vol. 7, no. 8, pp. 873-877, 2000.

[6] R. Khan, S. Arshed, W. Jehangir, S. Sen, and A. Yousif, "Cocaine-induced delayed myocardial infarction complicated by apical thrombus," Journal of Clinical Medicine Research, vol. 8, no. 1, pp. 59-61, 2016.

[7] A. Sarkar, A. Pande, G. N. Chandra, and I. Ahmed, "Acute myocardial infarction in a young cocaine addict with normal coronaries: time to raise awareness among emergency physicians," Indian Journal of Critical Care Medicine, vol. 17, no. 1, pp. 56-58, 2013.

[8] M. Graziani, L. Antonilli, A. R. Togna, M. C. Grassi, A. Badiani, and L. Saso, "Cardiovascular and hepatic toxicity of cocaine: potential beneficial effects of modulators of oxidative stress," Oxidative Medicine and Cellular Longevity, vol. 2016, no. 33, p. 8408479, 2016.

[9] L. Liaudet, B. Calderari, and P. Pacher, "Pathophysiological mechanisms of catecholamine and cocaine-mediated cardiotoxicity," Heart Failure Reviews, vol. 19, no. 6, pp. 815-824, 2014.

[10] B. G. Schwartz, S. Rezkalla, and R. A. Kloner, "Cardiovascular effects of cocaine," Circulation, vol. 122, no. 24, pp. 25582569, 2010.

[11] D. Cerretani, V. Fineschi, S. Bello, I. Riezzo, E. Turillazzi, and M. Neri, "Role of oxidative stress in cocaine-induced cardiotoxicity and cocaine-related death," Current Medicinal Chemistry, vol. 19, no. 33, pp. 5619-5623, 2012.

[12] D. C. Andersson, J. Fauconnier, T. Yamada et al., "Mitochondrial production of reactive oxygen species contributes to the beta-adrenergic stimulation of mouse cardiomycytes," The Journal of Physiology, vol. 589, no. Pt 7, pp. 1791-1801, 2011.

[13] L. Xiao, D. R. Pimentel, J. Wang, K. Singh, W. S. Colucci, and D. B. Sawyer, "Role of reactive oxygen species and $\mathrm{NAD}(\mathrm{P}) \mathrm{H}$ oxidase in alpha(1)-adrenoceptor signaling in adult rat cardiac myocytes," American Journal of Physiology. Cell Physiology, vol. 282, no. 4, pp. C926-C934, 2002.

[14] V.M. Costa, R. Silva, L. M. Ferreira et al., "Oxidation process of adrenaline in freshly isolated rat cardiomyocytes: formation of adrenochrome, quinoproteins, and GSH adduct," Chemical Research in Toxicology, vol. 20, no. 8, pp. 1183-1191, 2007.

[15] M. Neri, D. Cerretani, A. I. Fiaschi et al., "Correlation between cardiac oxidative stress and myocardial pathology due to acute and chronic norepinephrine administration in 
rats," Journal of Cellular and Molecular Medicine, vol. 11, no. 1, pp. 156-170, 2007.

[16] H. Pei, Y. Yang, H. Zhao et al., "The role of mitochondrial functional proteins in ROS production in ischemic heart diseases," Oxidative Medicine and Cellular Longevity, vol. 2016, p. 5470457, 2016.

[17] D. B. Zorov, C. R. Filburn, L. O. Klotz, J. L. Zweier, and S. J. Sollott, "Reactive oxygen species (ROS)-induced ROS release: a new phenomenon accompanying induction of the mitochondrial permeability transition in cardiac myocytes," The Journal of Experimental Medicine, vol. 192, no. 7, pp. 1001-1014, 2000.

[18] Z. V. Varga, P. Ferdinandy, L. Liaudet, and P. Pacher, "Druginduced mitochondrial dysfunction and cardiotoxicity," American Journal of Physiology. Heart and Circulatory Physiology, vol. 309, no. 9, pp. H1453-H1467, 2015.

[19] A. Vergeade, P. Mulder, C. Vendeville, R. Ventura-Clapier, C. Thuillez, and C. Monteil, "Xanthine oxidase contributes to mitochondrial ROS generation in an experimental model of cocaine-induced diastolic dysfunction," Journal of Cardiovascular Pharmacology, vol. 60, no. 6, pp. 538-543, 2012.

[20] A. Vergeade, P. Mulder, C. Vendeville-Dehaudt et al., "Mitochondrial impairment contributes to cocaine-induced cardiac dysfunction: prevention by the targeted antioxidant MitoQ," Free Radical Biology \& Medicine, vol. 49, no. 5, pp. 748-756, 2010.

[21] C. Yuan and D. Acosta Jr., "Cocaine-induced mitochondrial dysfunction in primary cultures of rat cardiomyocytes," Toxicology, vol. 112, no. 1, pp. 1-10, 1996.

[22] R. L. Grant and D. Acosta Jr., "A digitized fluorescence imaging study on the effects of local anesthetics on cytosolic calcium and mitochondrial membrane potential in cultured rabbit corneal epithelial cells," Toxicology and Applied Pharmacology, vol. 129, no. 1, pp. 23-35, 1994.

[23] F. Leon-Velarde, L. Huicho, and C. Monge, "Effects of cocaine on oxygen consumption and mitochondrial respiration in normoxic and hypoxic mice," Life Sciences, vol. 50, no. 3, pp. 213-218, 1992.

[24] B. G. Devi and A. W. Chan, "Impairment of mitochondrial respiration and electron transport chain enzymes during cocaine-induced hepatic injury," Life Sciences, vol. 60, no. 11, pp. 849-855, 1997.

[25] P. Mitchell, "Coupling of phosphorylation to electron and hydrogen transfer by a chemi-osmotic type of mechanism," Nature, vol. 191, no. 4784, pp. 144-148, 1961.

[26] R. A. Gottlieb and D. Bernstein, "Mitochondrial remodeling: rearranging, recycling, and reprogramming," Cell Calcium, vol. 60, no. 2, pp. 88-101, 2016.

[27] D. E. Green and A. Tzagoloff, "The mitochondrial electron transfer chain," Archives of Biochemistry and Biophysics, vol. 116, no. 1, pp. 293-304, 1966.

[28] C. R. Hackenbrock, B. Chazotte, and S. S. Gupte, "The random collision model and a critical assessment of diffusion and collision in mitochondrial electron transport," Journal of Bioenergetics and Biomembranes, vol. 18, no. 5, pp. 331368, 1986.

[29] M. L. Genova and G. Lenaz, "Functional role of mitochondrial respiratory supercomplexes," Biochimica et Biophysica Acta, vol. 1837, no. 4, pp. 427-443, 2014.

[30] M. E. Dalmonte, E. Forte, M. L. Genova, A. Giuffrè, P. Sarti, and G. Lenaz, "Control of respiration by cytochrome $c$ oxidase in intact cells: role of the membrane potential," The Journal of Biological Chemistry, vol. 284, no. 47, pp. 3233132335, 2009.

[31] G. Lenaz and M. L. Genova, "Structure and organization of mitochondrial respiratory complexes: a new understanding of an old subject," Antioxidants \& Redox Signaling, vol. 12, no. 8, pp. 961-1008, 2010.

[32] J. R. Friedman and J. Nunnari, "Mitochondrial form and function," Nature, vol. 505, no. 7483, pp. 335-343, 2014.

[33] C. Yuan and D. Acosta Jr., "Effect of cocaine on mitochondrial electron transport chain evaluated in primary cultures of neonatal rat myocardial cells and in isolated mitochondrial preparations," Drug and Chemical Toxicology, vol. 23, no. 2, pp. 339-348, 2000.

[34] R. J. Kaufman and J. D. Malhotra, "Calcium trafficking integrates endoplasmic reticulum function with mitochondrial bioenergetics," Biochimica et Biophysica Acta, vol. 1843, no. 10, pp. 2233-2239, 2014.

[35] M. Brini, T. Calì, D. Ottolini, and E. Carafoli, "Neuronal calcium signaling: function and dysfunction," Cellular and Molecular Life Sciences, vol. 71, no. 15, pp. 2787-2814, 2014.

[36] R. M. Case, D. Eisner, A. Gurney, O. Jones, S. Muallem, and A. Verkhratsky, "Evolution of calcium homeostasis: from birth of the first cell to an omnipresent signalling system," Cell Calcium, vol. 42, no. 4-5, pp. 345-350, 2007.

[37] P. Pinton, C. Giorgi, R. Siviero, E. Zecchini, and R. Rizzuto, "Calcium and apoptosis: ER-mitochondria Ca2+ transfer in the control of apoptosis," Oncogene, vol. 27, no. 50, pp. 6407-6418, 2008.

[38] A. Görlach, K. Bertram, S. Hudecova, and O. Krizanova, "Calcium and ROS: a mutual interplay," Redox Biology, vol. 6, pp. 260-271, 2015.

[39] M. J. Berridge, M. D. Bootman, and H. L. Roderick, "Calcium signalling: dynamics, homeostasis and remodelling," Nature Reviews. Molecular Cell Biology, vol. 4, no. 7, pp. 517-529, 2003.

[40] X. Tang, Y. X. Luo, H. Z. Chen, and D. P. Liu, "Mitochondria, endothelial cell function, and vascular diseases," Frontiers in Physiology, vol. 5, p. 175, 2014.

[41] S. Patergnani, J. M. Suski, C. Agnoletto et al., "Calcium signaling around mitochondria associated membranes (MAMs)," Cell Communication and Signaling: CCS, vol. 9, no. 1, p. 19, 2011.

[42] S. Marchi, S. Patergnani, and P. Pinton, "The endoplasmic reticulum-mitochondria connection: one touch, multiple functions," Biochimica et Biophysica Acta, vol. 1837, no. 4, pp. 461-469, 2014.

[43] M. Ahuja and S. Muallem, "The gatekeepers of mitochondrial calcium influx: MICU1 and MICU2," EMBO Reports, vol. 15, no. 3, pp. 205-206, 2014.

[44] D. Krizaj and D. R. Copenhagen, "Compartmentalization of calcium extrusion mechanisms in the outer and inner segments of photoreceptors," Neuron, vol. 21, no. 1, pp. 249256, 1998.

[45] G. C. Brailoiu, E. Deliu, L. M. Console-Bram et al., "Cocaine inhibits store-operated $\mathrm{Ca} 2+$ entry in brain microvascular endothelial cells: critical role for sigma-1 receptors," The Biochemical Journal, vol. 473, no. 1, pp. 1-5, 2016.

[46] J. A. Rosado, "Sigma-1 receptors: a new pathway for the modulation of store-operated calcium entry," The Biochemical Journal, vol. 473, no. 3, pp. e9-e10, 2016. 
[47] R. A. Smith and M. P. Murphy, "Animal and human studies with the mitochondria-targeted antioxidant MitoQ," Annals of the new York Academy of Sciences, vol. 1201, no. 1, pp. 96-103, 2010.

[48] G. Szabadkai and M. R. Duchen, "Mitochondria: The hub of cellular Ca2+ signaling," Physiology (Bethesda), vol. 23, no. 2, pp. 84-94, 2008.

[49] I. Kruman, Q. Guo, and M. P. Mattson, "Calcium and reactive oxygen species mediate staurosporine-induced mitochondrial dysfunction and apoptosis in PC12 cells," Journal of Neuroscience Research, vol. 51, no. 3, pp. 293308, 1998.

[50] K. Lynch, G. Fernandez, A. Pappalardo, and J. J. Peluso, "Basic fibroblast growth factor inhibits apoptosis of spontaneously immortalized granulosa cells by regulating intracellular free calcium levels through a protein kinase Cdelta-dependent pathway," Endocrinology, vol. 141, no. 11, pp. 4209-4217, 2000.

[51] S. Orrenius, B. Zhivotovsky, and P. Nicotera, "Regulation of cell death: the calcium-apoptosis link," Nature Reviews. Molecular Cell Biology, vol. 4, no. 7, pp. 552-565, 2003.

[52] B. Tombal, S. R. Denmeade, and J. T. Isaacs, “Assessment and validation of a microinjection method for kinetic analysis of $[\mathrm{Ca} 2+] \mathrm{i}$ in individual cells undergoing apoptosis," Cell Calcium, vol. 25, no. 1, pp. 19-28, 1999.

[53] R. B. Badisa, S. F. Darling-Reed, and C. B. Goodman, "Cocaine induces alterations in mitochondrial membrane potential and dual cell cycle arrest in rat c6 astroglioma cells," Neurochemical Research, vol. 35, no. 2, pp. 288297, 2010.

[54] P. Sarti, A. Giuffrè, M. C. Barone, E. Forte, D. Mastronicola, and M. Brunori, "Nitric oxide and cytochrome oxidase: reaction mechanisms from the enzyme to the cell," Free Radical Biology \& Medicine, vol. 34, no. 5, pp. 509-520, 2003.

[55] D. Mastronicola, E. Arcuri, M. Arese et al., "Morphine but not fentanyl and methadone affects mitochondrial membrane potential by inducing nitric oxide release in glioma cells," Cellular and Molecular Life Sciences, vol. 61, no. 23, pp. 2991-2997, 2004.

[56] M. Arese, M. C. Magnifico, D. Mastronicola et al., "Nanomolar melatonin enhances nNOS expression and controls HaCaT-cells bioenergetics," IUBMB Life, vol. 64, no. 3, pp. 251-258, 2012.

[57] P. Sarti, E. Forte, A. Giuffre, D. Mastronicola, M. C. Magnifico, and M. Arese, "The chemical interplay between nitric oxide and mitochondrial cytochrome c oxidase: reactions, effectors and pathophysiology," International Journal of Cell Biology, vol. 2012, p. 571067, 2012.

[58] P. Pacher, J. S. Beckman, and L. Liaudet, "Nitric oxide and peroxynitrite in health and disease," Physiological Reviews, vol. 87, no. 1, pp. 315-424, 2007.

[59] G. C. Brown and A. Vilalta, "How microglia kill neurons," Brain Research, vol. 1628, no. Pt B, pp. 288-297, 2015.

[60] A. Galkin and S. Moncada, "S-nitrosation of mitochondrial complex I depends on its structural conformation," The Journal of Biological Chemistry, vol. 282, no. 52, pp. 3744837453, 2007.

[61] D. J. Stuehr and C. F. Nathan, "Nitric oxide. A macrophage product responsible for cytostasis and respiratory inhibition in tumor target cells," The Journal of Experimental Medicine, vol. 169 , no. 5, pp. 1543-1555, 1989.
[62] P. I. Ortinski, "Cocaine-induced changes in NMDA receptor signaling," Molecular Neurobiology, vol. 50, no. 2, pp. 494506, 2014.

[63] P. Sarti, E. Lendaro, R. Ippoliti, A. Bellelli, P. A. Benedetti, and M. Brunori, "Modulation of mitochondrial respiration by nitric oxide: investigation by single cell fluorescence microscopy," The FASEB Journal, vol. 13, no. 1, pp. 191197, 1999.

[64] C. N. Hall and J. Garthwaite, "What is the real physiological NO concentration in vivo?" Nitric Oxide, vol. 21, no. 2, pp. 92-103, 2009.

[65] J. O. Lundberg, E. Weitzberg, and M. T. Gladwin, "The nitrate-nitrite-nitric oxide pathway in physiology and therapeutics," Nature Reviews. Drug Discovery, vol. 7, no. 2, pp. 156-167, 2008.

[66] Y. Itzhak, "Modulation of the PCP/NMDA receptor complex and sigma binding sites by psychostimulants," Neurotoxicology and Teratology, vol. 16, no. 4, pp. 363-368, 1994.

[67] Y. Itzhak, "Attenuation of cocaine kindling by 7-nitroindazole, an inhibitor of brain nitric oxide synthase," Neuropharmacology, vol. 35, no. 8, pp. 1065-1073, 1996.

[68] M. A. Balda, K. L. Anderson, and Y. Itzhak, "Adolescent and adult responsiveness to the incentive value of cocaine reward in mice: role of neuronal nitric oxide synthase (nNOS) gene," Neuropharmacology, vol. 51, no. 2, pp. 341-349, 2006.

[69] F. J. Nasif, X. T. Hu, O. A. Ramirez, and M. F. Perez, "Inhibition of neuronal nitric oxide synthase prevents alterations in medial prefrontal cortex excitability induced by repeated cocaine administration," Psychopharmacology, vol. 218, no. 2, pp. 323-330, 2011.

[70] S. Liddie, M. A. Balda, and Y. Itzhak, "Nitric oxide (NO) signaling as a potential therapeutic modality against psychostimulants," Current Pharmaceutical Design, vol. 19, no. 40, pp. 7092-7102, 2013.

[71] A. Frustaci, M. A. Russo, E. Morgante et al., "Oxidative myocardial damage in human cocaine-related cardiomyopathy," European Journal of Heart Failure, vol. 17, no. 3, pp. 283290, 2015.

[72] V. Vitcheva, R. Simeonova, M. Kondeva-Burdina, and M. Mitcheva, "Selective nitric oxide synthase inhibitor 7-nitroindazole protects against cocaine-induced oxidative stress in rat brain," Oxidative Medicine and Cellular Longevity, vol. 2015, p. 157876, 2015.

[73] A. Masini, D. Gallesi, F. Giovannini, T. Trenti, and D. Ceccarelli, "Membrane potential of hepatic mitochondria after acute cocaine administration in rats-the role of mitochondrial reduced glutathione," Hepatology, vol. 25, no. 2, pp. 385390, 1997.

[74] N. D. Volkow, J. S. Fowler, A. P. Wolf et al., "Distribution and kinetics of carbon-11-cocaine in the human body measured with PET," Journal of Nuclear Medicine, vol. 33, no. 4, pp. 521-525, 1992.

[75] M. Portugal-Cohen, R. Numa, R. Yaka, and R. Kohen, "Cocaine induces oxidative damage to skin via xanthine oxidase and nitric oxide synthase," Journal of Dermatological Science, vol. 58, no. 2, pp. 105-112, 2010.

[76] P. Kovacic, "Unifying mechanism for bacterial cell signalers (4,5-dihydroxy-2,3-pentanedione, lactones and oligopeptides): electron transfer and reactive oxygen species. Practical medical features," Medical Hypotheses, vol. 69, no. 5, pp. 1105-1110, 2007. 
[77] C. M. Liou, S. C. Tsai, C. H. Kuo, H. Ting, and S. D. Lee, "Cardiac Fas-dependent and mitochondria-dependent apoptosis after chronic cocaine abuse," International Journal of Molecular Sciences, vol. 15, no. 4, pp. 5988-6001, 2014.

[78] B. J. Borkowski, Y. Cheema, A. U. Shahbaz, S. K. Bhattacharya, and K. T. Weber, "Cation dyshomeostasis and cardiomyocyte necrosis: the Fleckenstein hypothesis revisited," European Heart Journal, vol. 32, no. 15, pp. 1846-1853, 2011.

[79] D. M. Bers, "Cardiac excitation-contraction coupling," Nature, vol. 415, no. 6868, pp. 198-205, 2002.

[80] J. J. Lemasters, T. Qian, C. A. Bradham et al., "Mitochondrial dysfunction in the pathogenesis of necrotic and apoptotic cell death," Journal of Bioenergetics and Biomembranes, vol. 31, no. 4, pp. 305-319, 1999.

[81] M. U. Khan, Y. Cheema, A. U. Shahbaz et al., "Mitochondria play a central role in nonischemic cardiomyocyte necrosis: common to acute and chronic stressor states," Pflügers Archiv, vol. 464, no. 1, pp. 123-131, 2012.

[82] A. I. Tarasov, E. J. Griffiths, and G. A. Rutter, "Regulation of ATP production by mitochondrial $\mathrm{Ca}(2+)$," Cell Calcium, vol. 52, no. 1, pp. 28-35, 2012.

[83] T. Cunha-Oliveira, L. Silva, A. M. Silva, A. J. Moreno, C. R. Oliveira, and M. S. Santos, "Mitochondrial complex I dysfunction induced by cocaine and cocaine plus morphine in brain and liver mitochondria," Toxicology Letters, vol. 219, no. 3, pp. 298-306, 2013.

[84] A. G. Fantel, C. V. Barber, M. B. Carda, R. W. Tumbic, and B. Mackler, "Studies of the role of ischemia/reperfusion and superoxide anion radical production in the teratogenicity of cocaine," Teratology, vol. 46, no. 3, pp. 293-300, 1992.

[85] Q. Chen, A. K. Camara, D. F. Stowe, C. L. Hoppel, and E. J. Lesnefsky, "Modulation of electron transport protects cardiac mitochondria and decreases myocardial injury during ischemia and reperfusion," American Journal of Physiology. Cell Physiology, vol. 292, no. 1, pp. C137-C147, 2007.

[86] A. Remondino, S. H. Kwon, C. Communal et al., "Betaadrenergic receptor-stimulated apoptosis in cardiac myocytes is mediated by reactive oxygen species/c-Jun NH2-terminal kinase-dependent activation of the mitochondrial pathway," Circulation Research, vol. 92, no. 2, pp. 136-138, 2003.

[87] Y. Xiao, J. He, R. D. Gilbert, and L. Zhang, "Cocaine induces apoptosis in fetal myocardial cells through a mitochondriadependent pathway," The Journal of Pharmacology and Experimental Therapeutics, vol. 292, no. 1, pp. 8-14, 2000.

[88] J. He, Y. Xiao, C. A. Casiano, and L. Zhang, "Role of mitochondrial cytochrome $\mathrm{c}$ in cocaine-induced apoptosis in coronary artery endothelial cells," The Journal of Pharmacology and Experimental Therapeutics, vol. 295, no. 3, pp. 896-903, 2000.

[89] M. Alvaro-Bartolome, R. La Harpe, L. F. Callado, J. J. Meana, and J. A. García-Sevilla, "Molecular adaptations of apoptotic pathways and signaling partners in the cerebral cortex of human cocaine addicts and cocaine-treated rats," Neuroscience, vol. 196, pp. 1-15, 2011.

[90] A. J. Kowaltowski, N. C. de Souza-Pinto, R. F. Castilho, and A. E. Vercesi, "Mitochondria and reactive oxygen species," Free Radical Biology \& Medicine, vol. 47, no. 4, pp. 333343, 2009.

[91] D. B. Zorov, M. Juhaszova, and S. J. Sollott, "Mitochondrial reactive oxygen species (ROS) and ROS-induced ROS release," Physiological Reviews, vol. 94, no. 3, pp. 909-950, 2014.
[92] D. B. Zorov, M. Juhaszova, and S. J. Sollott, "Mitochondrial ROS-induced ROS release: an update and review," Biochimica et Biophysica Acta, vol. 1757, no. 5-6, pp. 509-517, 2006.

[93] V. M. Costa, F. Carvalho, M. L. Bastos, R. A. Carvalho, M. Carvalho, and F. Remiao, "Contribution of catecholamine reactive intermediates and oxidative stress to the pathologic features of heart diseases," Current Medicinal Chemistry, vol. 18, no. 15, pp. 2272-2314, 2011.

[94] A. Bindoli, M. P. Rigobello, and D. J. Deeble, "Biochemical and toxicological properties of the oxidation products of catecholamines," Free Radical Biology \& Medicine, vol. 13, no. 4, pp. 391-405, 1992.

[95] A. Bindoli, D. J. Deeble, M. P. Rigobello, and L. Galzigna, "Direct and respiratory chain-mediated redox cycling of adrenochrome," Biochimica et Biophysica Acta, vol. 1016, no. 3, pp. 349-356, 1990.

[96] G. S. Behonick, M. J. Novak, E. W. Nealley, and S. I. Baskin, "Toxicology update: the cardiotoxicity of the oxidative stress metabolites of catecholamines (aminochromes)," Journal of Applied Toxicology, vol. 21, Suppl 1, pp. S15-S22, 2001.

[97] M. L. Genova, N. M. Abd-Elsalam, M. E. El Sayed et al., "Redox cycling of adrenaline and adrenochrome catalysed by mitochondrial complex I," Archives of Biochemistry and Biophysics, vol. 447, no. 2, pp. 167-173, 2006.

[98] G. M. Taam, S. Takeo, A. Ziegelhoffer, P. K. Singal, R. E. Beamish, and N. S. Dhalla, "Effect of adrenochrome on adenine nucleotides and mitochondrial oxidative phosphorylation in rat heart," The Canadian Journal of Cardiology, vol. 2, no. 2, pp. 88-93, 1986.

[99] N. Kaludercic, J. Mialet-Perez, N. Paolocci, A. Parini, and F. Di Lisa, "Monoamine oxidases as sources of oxidants in the heart," Journal of Molecular and Cellular Cardiology, vol. 73, pp. 34-42, 2014.

[100] H. C. Stanton and A. Schwartz, "Effects of a hydrazine monoamine oxidase inhibitor (phenelzine) on isoproterenolinduced myocardiopathies in the rat," The Journal of Pharmacology and Experimental Therapeutics, vol. 157, no. 3, pp. 649658, 1967.

[101] M. Isabelle, C. Monteil, F. Moritz et al., "Role of alpha1adrenoreceptors in cocaine-induced NADPH oxidase expression and cardiac dysfunction," Cardiovascular Research, vol. 67, no. 4, pp. 699-704, 2005.

[102] M. Isabelle, A. Vergeade, F. Moritz et al., "NADPH oxidase inhibition prevents cocaine-induced up-regulation of xanthine oxidoreductase and cardiac dysfunction," Journal of Molecular and Cellular Cardiology, vol. 42, no. 2, pp. 326332, 2007.

[103] E. Barth, G. Stämmler, B. Speiser, and J. Schaper, "Ultrastructural quantitation of mitochondria and myofilaments in cardiac muscle from 10 different animal species including man," Journal of Molecular and Cellular Cardiology, vol. 24, no. 7, pp. 669-681, 1992.

[104] S. M. Davidson, "Endothelial mitochondria and heart disease," Cardiovascular Research, vol. 88, no. 1, pp. 58-66, 2010.

[105] S. Serpillon, B. C. Floyd, R. S. Gupte et al., "Superoxide production by $\mathrm{NAD}(\mathrm{P}) \mathrm{H}$ oxidase and mitochondria is increased in genetically obese and hyperglycemic rat heart and aorta before the development of cardiac dysfunction. The role of glucose-6-phosphate dehydrogenase-derived NADPH," American Journal of Physiology. Heart and Circulatory Physiology, vol. 297, no. 1, pp. H153-H162, 2009. 
[106] R. M. Lebovitz, H. Zhang, H. Vogel et al., "Neurodegeneration, myocardial injury, and perinatal death in mitochondrial superoxide dismutase-deficient mice," Proceedings of the National Academy of Sciences of the United States of America, vol. 93, no. 18, pp. 9782-9787, 1996.

[107] D. N. Granger and P. R. Kvietys, "Reperfusion injury and reactive oxygen species: the evolution of a concept," Redox Biology, vol. 6, pp. 524-551, 2015.

[108] J. M. McCord, R. S. Roy, and S. W. Schaffer, "Free radicals and myocardial ischemia. The role of xanthine oxidase," Advances in Myocardiology, vol. 5, pp. 183-189, 1985.

[109] S. Baldus, K. Müllerleile, P. Chumley et al., "Inhibition of xanthine oxidase improves myocardial contractility in patients with ischemic cardiomyopathy," Free Radical Biology \& Medicine, vol. 41, no. 8, pp. 1282-1288, 2006.

[110] J. Frijhoff, P. G. Winyard, N. Zarkovic et al., "Clinical relevance of biomarkers of oxidative stress," Antioxidants \& Redox Signaling, vol. 23, no. 14, pp. 1144-1170, 2015.

[111] WHO, Biomarkers in Risk Assessment: Validity and Validation, WHO, Geneva, Switzerland, 2001.

[112] H. Solhi, A. Malekirad, A. Mohammad Kazemifar, and F. Sharif, "Oxidative stress and lipid peroxidation in prolonged users of methamphetamine," Drug Metabolism Letters, vol. 7, no. 2, pp. 79-82, 2014.

[113] J. S. Womersley and J. D. Uys, "S-Glutathionylation and redox protein signaling in drug addiction," Progress in Molecular Biology and Translational Science, vol. 137, pp. 87-121, 2016.

[114] J. A. Hernandez, R. C. Lopez-Sanchez, and A. RendonRamirez, "Lipids and oxidative stress associated with ethanol-induced neurological damage," Oxidative Medicine and Cellular Longevity, vol. 2016, p. 1543809, 2016.

[115] T. A. Zima, L. Fialová, O. Mestek et al., "Oxidative stress, metabolism of ethanol and alcohol-related diseases," Journal of Biomedical Science, vol. 8, no. 1, pp. 59-70, 2001.

[116] M. C. Huang, C. H. Chen, F. C. Peng, S. H. Tang, and C. C. Chen, "Alterations in oxidative stress status during early alcohol withdrawal in alcoholic patients," Journal of the Formosan Medical Association, vol. 108, no. 7, pp. 560-569, 2009.

[117] A. O. Sordi, F. Pechansky, F. H. Kessler et al., "Oxidative stress and BDNF as possible markers for the severity of crack cocaine use in early withdrawal," Psychopharmacology, vol. 231, no. 20, pp. 4031-4039, 2014.

[118] D. Del Rio, A. J. Stewart, and N. Pellegrini, “A review of recent studies on malondialdehyde as toxic molecule and biological marker of oxidative stress," Nutrition, Metabolism, and Cardiovascular Diseases, vol. 15, no. 4, pp. 316-328, 2005.

[119] E. Niki, "Lipid peroxidation products as oxidative stress biomarkers," BioFactors, vol. 34, no. 2, pp. 171-180, 2008.

[120] L. Pomierny-Chamioło, A. Moniczewski, K. Wydra, A. Suder, and M. Filip, "Oxidative stress biomarkers in some rat brain structures and peripheral organs underwent cocaine," Neurotoxicity Research, vol. 23, no. 1, pp. 92-102, 2013.

[121] V. Fineschi, G. Baroldi, F. Centini et al., "Markers of cardiac oxidative stress and altered morphology after intraperitoneal cocaine injection in a rat model," International Journal of Legal Medicine, vol. 114, no. 6, pp. 323-330, 2001.

[122] F. Moritz, C. Monteil, M. Isabelle et al., "Role of reactive oxygen species in cocaine-induced cardiac dysfunction," Cardiovascular Research, vol. 59, no. 4, pp. 834-843, 2003.
[123] J. Walker, T. Winhusen, J. M. Storkson et al., “Total antioxidant capacity is significantly lower in cocaine-dependent and methamphetamine-dependent patients relative to normal controls: results from a preliminary study," Human Psychopharmacology, vol. 29, no. 6, pp. 537-543, 2014.

[124] F. Freitas, N. Brucker, J. Durgante et al., "Urinary 1hydroxypyrene is associated with oxidative stress and inflammatory biomarkers in acute myocardial infarction," International Journal of Environmental Research and Public Health, vol. 11, no. 9, pp. 9024-9037, 2014.

[125] I. L. Megson, S. J. Haw, D. E. Newby, and J. P. Pell, “Association between exposure to environmental tobacco smoke and biomarkers of oxidative stress among patients hospitalised with acute myocardial infarction," PLoS One, vol. 8, no. 12, article e81209, 2013.

[126] C. C. de Farias, M. Maes, K. L. Bonifácio et al., "Highly specific changes in antioxidant levels and lipid peroxidation in Parkinson's disease and its progression: disease and staging biomarkers and new drug targets," Neuroscience Letters, vol. 617, pp. 66-71, 2016.

[127] M. Schrag, C. Mueller, M. Zabel et al., "Oxidative stress in blood in Alzheimer's disease and mild cognitive impairment: a meta-analysis," Neurobiology of Disease, vol. 59, pp. 100110, 2013.

[128] J. C. Narvaez, P. V. Magalhães, G. R. Fries et al., "Peripheral toxicity in crack cocaine use disorders," Neuroscience Letters, vol. 544, pp. 80-84, 2013.

[129] J. C. Narvaez, P. V. Magalhães, G. R. Fries et al., "Repeated exposure to cocaine differently modulates BDNF mRNA and protein levels in rat striatum and prefrontal cortex," The European Journal of Neuroscience, vol. 26, no. 10, pp. 2756-2763, 2007.

[130] X. Y. Zhang, D. C. Chen, Y. L. Tan et al., "The interplay between BDNF and oxidative stress in chronic schizophrenia," Psychoneuroendocrinology, vol. 51, pp. 201-208, 2015.

[131] R. Pacifici, A. I. Fiaschi, L. Micheli et al., "Immunosuppression and oxidative stress induced by acute and chronic exposure to cocaine in rat," International Immunopharmacology, vol. 3, no. 4, pp. 581-592, 2003.

[132] C. He, P. C. Hart, D. Germain, and M. G. Bonini, "SOD2 and the mitochondrial UPR: partners regulating cellular phenotypic transitions," Trends in Biochemical Sciences, vol. 41, no. 7, pp. 568-577, 2016.

[133] I. N. Zelko, T. J. Mariani, and R. J. Folz, "Superoxide dismutase multigene family: a comparison of the CuZn-SOD (SOD1), Mn-SOD (SOD2), and EC-SOD (SOD3) gene structures, evolution, and expression," Free Radical Biology \& Medicine, vol. 33, no. 3, pp. 337-349, 2002.

[134] A. Y. Andreyev, Y. E. Kushnareva, and A. A. Starkov, "Mitochondrial metabolism of reactive oxygen species," Biochemistry (Mosc), vol. 70, no. 2, pp. 200-214, 2005.

[135] M. Che, R. Wang, X. Li, H. Y. Wang, and X. S. Zheng, "Expanding roles of superoxide dismutases in cell regulation and cancer," Drug Discovery Today, vol. 21, no. 1, pp. 143-149, 2016.

[136] S. L. Marklund, "Extracellular superoxide dismutase in human tissues and human cell lines," The Journal of Clinical Investigation, vol. 74, no. 4, pp. 1398-1403, 1984.

[137] A. Okado-Matsumoto and I. Fridovich, "Subcellular distribution of superoxide dismutases (SOD) in rat liver: $\mathrm{Cu}, \mathrm{Zn}-\mathrm{SOD}$ in mitochondria," The Journal of Biological Chemistry, vol. 276, no. 42, pp. 38388-38393, 2001. 
[138] R. López-Pedrajas, D. T. Ramírez-Lamelas, B. Muriach et al., "Cocaine promotes oxidative stress and microglialmacrophage activation in rat cerebellum," Frontiers in Cellular Neuroscience, vol. 9, p. 279, 2015.

[139] J. D. Uys, L. Knackstedt, P. Hurt et al., "Cocaine-induced adaptations in cellular redox balance contributes to enduring behavioral plasticity," Neuropsychopharmacology, vol. 36, no. 12, pp. 2551-2560, 2011.

[140] P. Ghezzi, "Protein glutathionylation in health and disease," Biochimica et Biophysica Acta, vol. 1830, no. 5, pp. 31653172, 2013.

[141] W. A. Kleinman, D. Komninou, Y. Leutzinger et al., "Protein glutathiolation in human blood," Biochemical Pharmacology, vol. 65, no. 5, pp. 741-746, 2003.

[142] H. J. Chen, W. P. Lin, S. D. Chiu, and C. H. Fan, "Multistage mass spectrometric analysis of human hemoglobin glutathionylation: correlation with cigarette smoking," Chemical Research in Toxicology, vol. 27, no. 5, pp. 864-872, 2014.

[143] J. E. Muscat, W. Kleinman, S. Colosimo et al., "Enhanced protein glutathiolation and oxidative stress in cigarette smokers," Free Radical Biology \& Medicine, vol. 36, no. 4, pp. 464-470, 2004.

[144] O. Firuzi, R. Miri, M. Tavakkoli, and L. Saso, "Antioxidant therapy: current status and future prospects," Current Medicinal Chemistry, vol. 18, no. 25, pp. 3871-3888, 2011.

[145] L. Saso and O. Firuzi, "Pharmacological applications of antioxidants: lights and shadows," Current Drug Targets, vol. 15, no. 13, pp. 1177-1199, 2014.

[146] J. D. Gladden, B. R. Zelickson, C. C. Wei et al., "Novel insights into interactions between mitochondria and xanthine oxidase in acute cardiac volume overload," Free Radical Biology \& Medicine, vol. 51, no. 11, pp. 1975-1984, 2011.

[147] D. M. Yancey, J. L. Guichard, M. I. Ahmed et al., "Cardiomyocyte mitochondrial oxidative stress and cytoskeletal breakdown in the heart with a primary volume overload," American Journal of Physiology. Heart and Circulatory Physiology, vol. 308, no. 6, pp. H651-H663, 2015.

[148] R. A. Smith and M. P. Murphy, "Mitochondria-targeted antioxidants as therapies," Discovery Medicine, vol. 11, no. 57, pp. 106-114, 2011.

[149] M. Erb, B. Hoffmann-Enger, H. Deppe et al., "Features of idebenone and related short-chain quinones that rescue ATP levels under conditions of impaired mitochondrial complex I," PLoS One, vol. 7, no. 4, article e36153, 2012.

[150] A. Mordente, G. E. Martorana, G. Minotti, and B. Giardina, "Antioxidant properties of 2,3-dimethoxy-5-methyl-6-(10hydroxydecyl)-1,4-benzoquinone (idebenone)," Chemical Research in Toxicology, vol. 11, no. 1, pp. 54-63, 1998.

[151] V. Giorgio, V. Petronilli, A. Ghelli et al., "The effects of idebenone on mitochondrial bioenergetics," Biochimica et Biophysica Acta, vol. 1817, no. 2, pp. 363-369, 2011.

[152] A. Sadakierska-Chudy, M. Frankowska, and M. Filip, "Mitoepigenetics and drug addiction," Pharmacology \& Therapeutics, vol. 144, no. 2, pp. 226-233, 2014.

[153] J. D. Gladden, B. R. Zelickson, J. L. Guichard et al., "Xanthine oxidase inhibition preserves left ventricular systolic but not diastolic function in cardiac volume overload," American Journal of Physiology. Heart and Circulatory Physiology, vol. 305, no. 10, pp. H1440-H1450, 2013.
[154] N. Engberding, S. Spiekermann, A. Schaefer et al., "Allopurinol attenuates left ventricular remodeling and dysfunction after experimental myocardial infarction: a new action for an old drug?" Circulation, vol. 110, no. 15, pp. 2175-2179, 2004.

[155] T. P. Cappola, D. A. Kass, G. S. Nelson et al., “Allopurinol improves myocardial efficiency in patients with idiopathic dilated cardiomyopathy," Circulation, vol. 104, no. 20, pp. 2407-2411, 2001. 


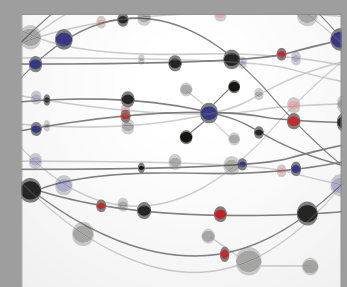

The Scientific World Journal
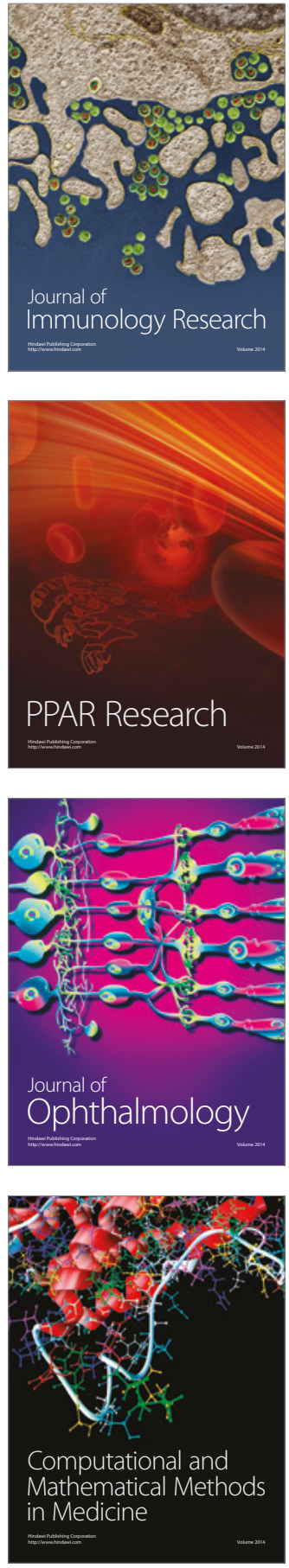

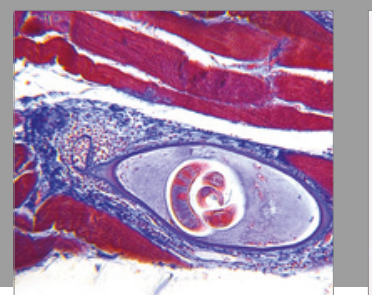

Gastroenterology Research and Practice
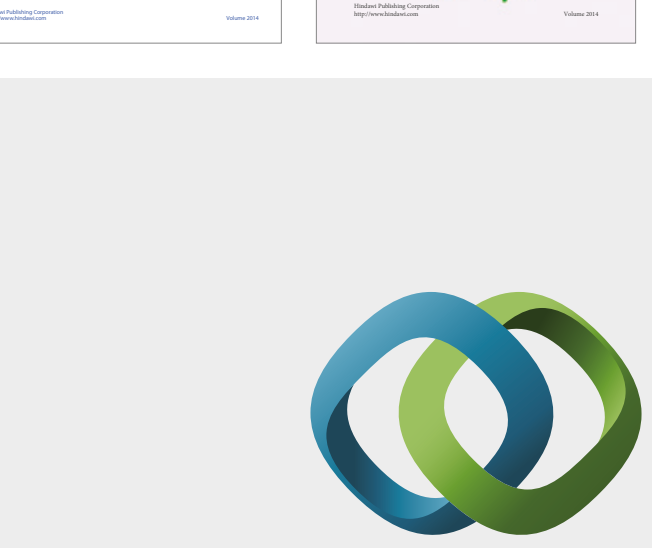

\section{Hindawi}

Submit your manuscripts at

https://www.hindawi.com
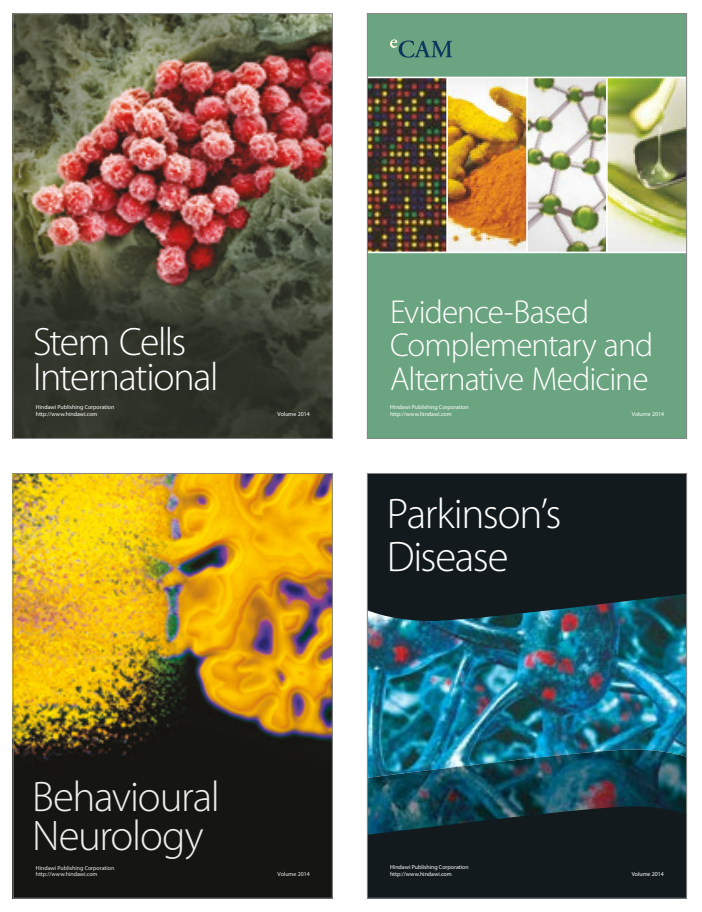
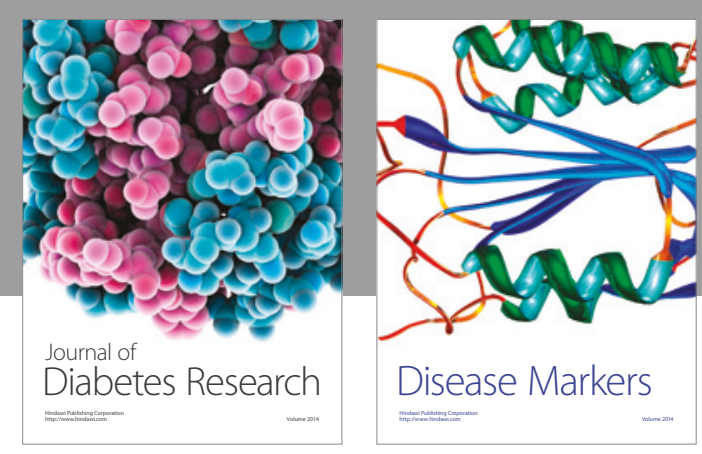

Disease Markers
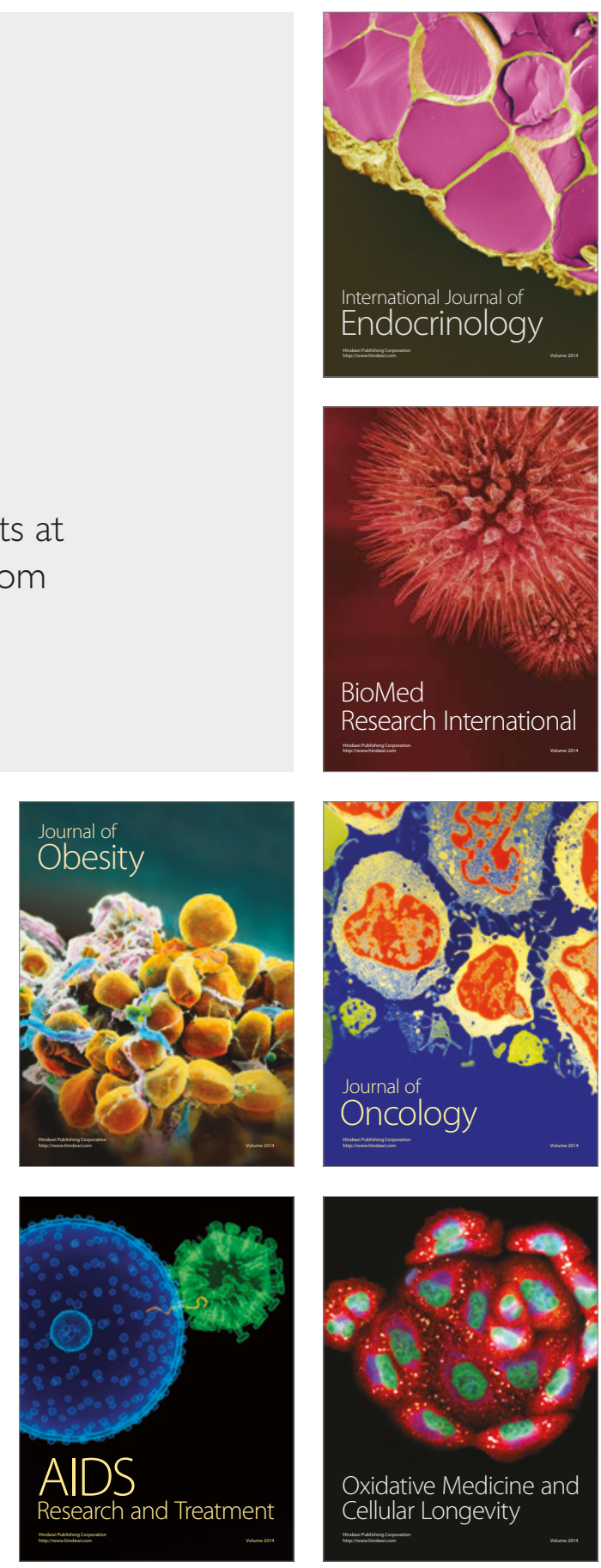